\title{
Retinal vasculature development in health and disease
} Senthil Selvam ${ }^{1,2^{*}}$, Tejas Kumar $^{3^{*}}$ and Marcus Fruttiger ${ }^{15}$

1 UCL Institute of Ophthalmology, University College London, 11-43 Bath Street, London EC1V 9EL, United Kingdom.

2 NIHR Biomedical Research Centre for Ophthalmology, Moorfields Eye Hospital NHS Foundation Trust and UCL Institute of Ophthalmology, London, United Kingdom.

3 Monash School of Medicine, Monash University, Clayton Campus, Melbourne, VIC, 3800, Australia

* both authors contributed equally to this manuscript

$\S$ Corresponding author: $\underline{\text { m.fruttiger@ucl.ac.uk }}$

\begin{abstract}
Development of the retinal vasculature is based on highly coordinated signalling between different cell types of the retina, integrating internal metabolic requirements with external influences such as the supply of oxygen and nutrients. The developing mouse retinal vasculature is a useful model system to study these interactions because it is experimentally accessible for intra ocular injections and genetic manipulations, can be easily imaged and develops in a similar fashion to that of humans. Research using this model has provided insights about general principles of angiogenesis as well as pathologies that affect the developing retinal vasculature. In this review, we discuss recent advances in our understanding of the molecular and cellular mechanisms that govern the interactions between neurons, glial and vascular cells in the developing retina. This includes a review of mechanisms that shape the retinal vasculature, such as sprouting angiogenesis, vascular network remodelling and vessel maturation. We also explore how the disruption of these processes in mice can lead to pathology - such as oxygen induced retinopathy - and how this translates to human retinopathy of prematurity.
\end{abstract}

\section{Content}

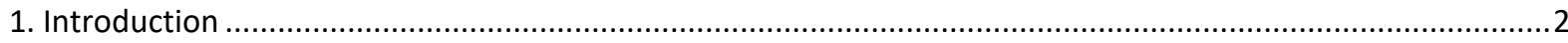

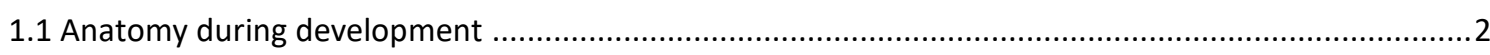

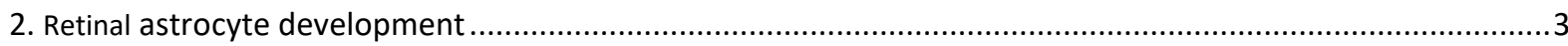

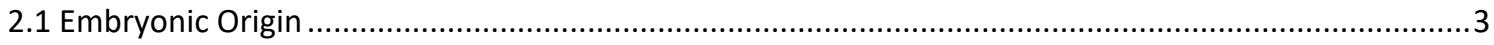

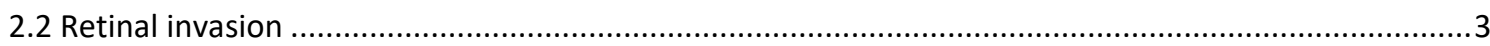

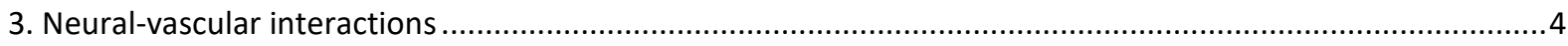

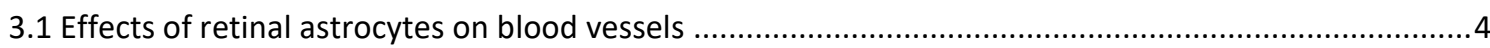

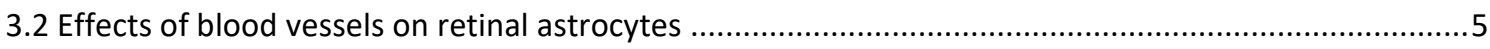

3.3 Role of RGCs in regulating retinal vasculature development ........................................................5

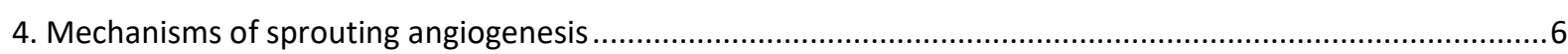

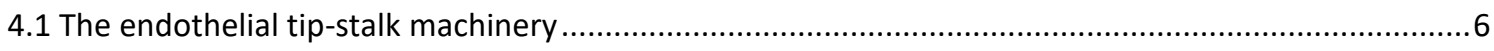

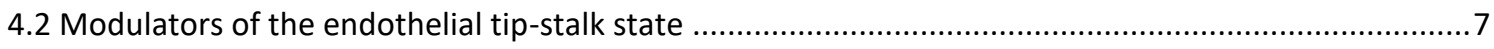

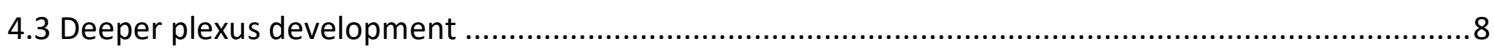

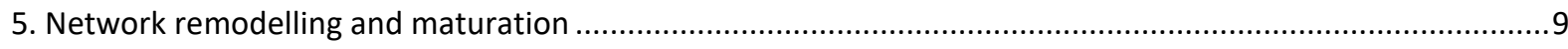

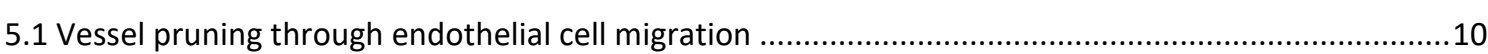

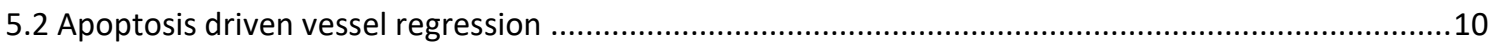

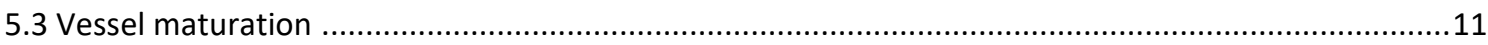

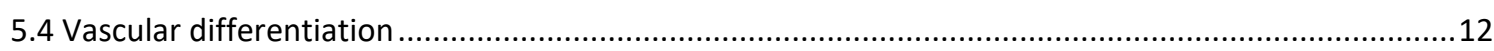

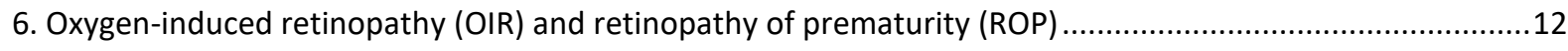

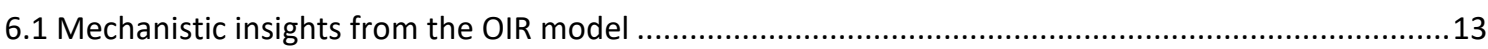

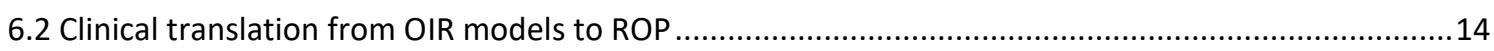

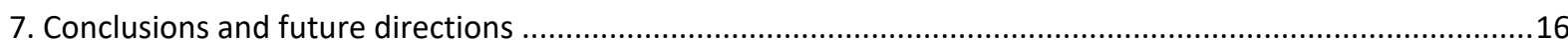

8. References 


\section{Introduction}

Retinal vasculature is arguably the most studied vascular bed in the entire body. It can be readily imaged in living patients with ever increasing technical sophistication, which is exploited in an expanding range of fields (Bajwa et al., 2015; Cheung et al., 2017). Furthermore, the developing mouse retinal vasculature has become a hugely successful model system to study the basic biology of vascular growth. In particular, the introduction of inducible genetic mouse models has opened up the study of signalling pathways involved in postnatal retinal vasculature development. This has potential translational value in many areas, as there are numerous human conditions affected by pathological angiogenesis (Coorey et al., 2012; Stahl et al., 2010b; Ye, 2016). Through such models, our understanding of the cellular and molecular mechanisms driving angiogenesis and the development of the retinal vasculature has improved considerably in recent years. Similar inroads have also been made in understanding abnormal retinal vasculature development in pathologies such as familial exudative vitreoretinopathy (FEVR), retinopathy of prematurity (ROP) and oxygen induced retinopathy (OIR). Here we review the latest advances in understanding how this unique vascular network develops under physiological as well as pathological conditions.

\subsection{Anatomy during development}

The main function of the retinal vasculature is to metabolically sustain the inner part of the retina via a laminar meshwork of capillaries that permeates the neural tissue. In contrast, the outer retina (containing photoreceptors) is avascular and supplied by the choroidal vasculature, which is separated from the neural retina only by the retinal pigment epithelium (RPE). Direct vascularisation of the inner retina is an "invention" of the mammalian lineage and is not seen in lower vertebrates, where oxygen and nutrients are delivered to the inner retina by vitreal vessels (Chase, 1982). This evolutionary older design can still be found in mammals during embryonic development, but vascular remodelling later leads to regression of these transient vitreal vessels (called the hyaloid vasculature), whilst new vessels grow into the retina from the optic nerve head. These new vessels initially form a flat, primary plexus in the nerve fibre layer that subsequently sprouts into the retina, establishing a secondary, deeper plexus.

In humans, hyaloid vasculature formation, its regression and most retinal vasculature development all occur in utero. The hyaloid vasculature originates from the central hyaloid artery, which is folded into the optic vesicle during optic fissure closure at around 6 weeks of gestation (WG) (Gray and Lewis, 1918). It runs from the centre of the optic disc through the vitreous to the posterior lens and eventually drains into choroidal veins (Fig. 1) (Anand-Apte and Hollyfield, 2010; Saint-Geniez and D'Amore, 2004). It consists of the hyaloid artery $(\mathrm{HA})$, vasculosa hyaloidea propria (VHP), tunica vasculosa lentis (TVL) and pupillary membrane (PM). Branching of the hyaloid artery over the posterior lens surface forms the TVL. As the TVL expands

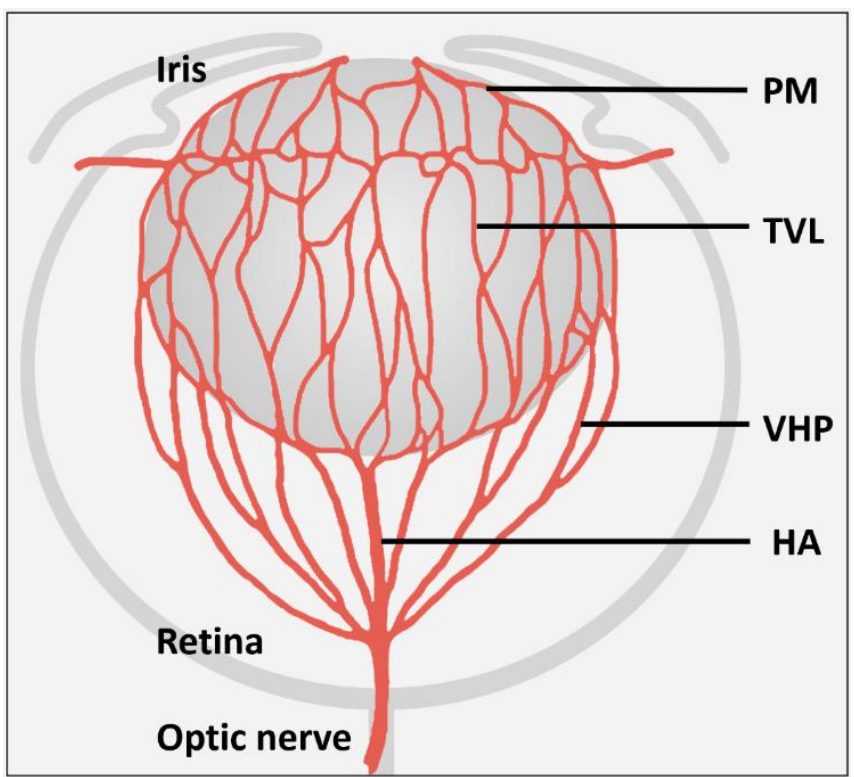

Fig. 1 Anatomy of the hyaloid vasculature in the developing eye. The Hyaloid Artery (HA) emerges from the optic nerve head, branches over the posterior lens as the Tunica Vasculosa Lentis (TVL) and becomes the Pupillary Membrane (PM) anteriorly. The Vasa Hyaloidea Propria emerges from the HA, anastomosing with the TVL.

around the anterior part of the lens, it forms the PM, eventually draining into choroidal circulation (Saint-Geniez and D'Amore, 2004). The VHP, also derived from the HA, branches from a more proximal position. Whilst initially sitting on the retina, the VHP gradually lifts off and joins the $T V L$ close to the equator of the lens as the eye increases in size and subsequently does not anastomose with the retinal vasculature (Ito and Yoshioka, 1999). The regression of hyaloid vessels begins around 13 weeks of gestation (WG) (Zhu et al., 2000) and the concomitant formation of the primary plexus starts around 15 WG, emerging from an existing capillary ring at the optic nerve head and spreading across the inner surface of the retina (Provis, 2001) in four main lobes. The primary plexus reaches the retinal periphery nasally at 36 WG and temporally at around 40 WG (Gariano, 2003; Provis, 2001). At 25-26 WG, deeper plexus components form by angiogenic sprouting from the primary plexus veins (Fruttiger, 2007; Hughes et al., 2000; Provis, 2001). These sprouts penetrate into the retina and establish two laminar networks on either side of the inner nuclear layer (INL) (Gariano et al., 1994). Deeper plexus vessel growth occurs from the centre to periphery, in the same outward expanding manner as the primary plexus. Unlike the rest of the retina, the foveal zone remains completely devoid of vessels throughout development (Gariano and Gardner, 2005). Retinal vascularization is complete by $38-40$ WG, by which time the hyaloid system has also fully regressed (Duke-Elder, n.d.; Mann, 1950).

In mice, retinal vasculature development unfolds in a similar way to humans, but begins postnatally. The first retinal vessels sprout from the optic nerve head around birth, forming an expanding network (the primary plexus) that reaches the periphery around postnatal day (P)7 (Fruttiger, 2007). It consists of alternating, arterial-venous loops and is radially symmetrical (Fig. 2A). At P7 the deeper plexus starts 

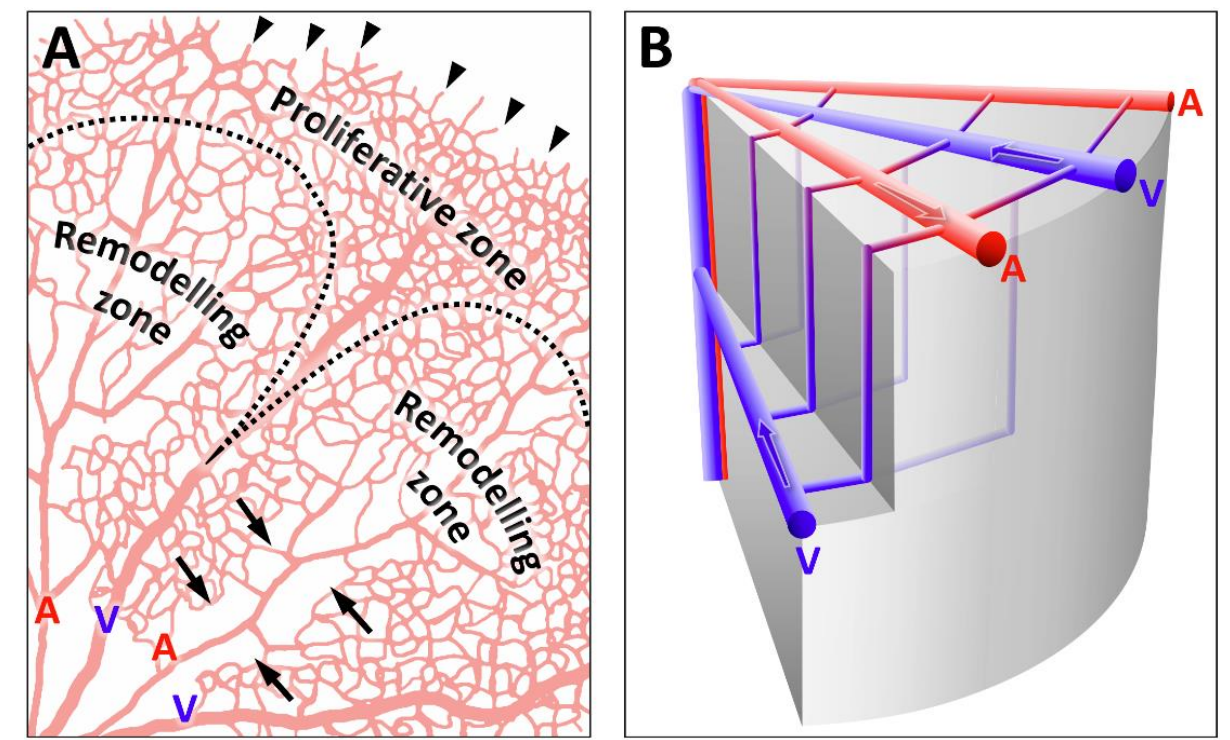

Fig. 2 (A) The developing mouse primary plexus (at P5) is radially symmetric and can be divided into a proliferative zone at the growing edge and a remodelling zone more centrally. Arrowheads indicate tip cells, arrows show capillary free zones around arteries (labelled A, veins are labelled V). (B) Deeper plexus development leads to two vascular networks in the adult that share the same arterial supply but are drained either through the superficial or deeper plexus veins.

to grow from veins in the primary plexus, penetrating the retina and establishing a laminar network around the INL, as in humans (Stahl et al., 2010b). Deeper plexus development is completed in the third postnatal week, by which point the hyaloid vessels have fully regressed. During this period, some of the major radial veins in the primary plexus relocate into the deeper plexus via vascular network remodelling. Apart from the involvement of apelin signalling, the mechanisms underlying this process are not well understood (McKenzie et al., 2012). Unlike the veins, all the arteries remain in the primary plexus, which results in two distinct capillary beds (primary plexus and deeper plexus) that share an arterial supply but have different venous drainage (Fig. 2B). Hyaloid vascular regression in mice also occurs postnatally with the VHP and TVL regressing sharply between P4 and P8, and the PM exhibiting a steady rate of regression (Ito and Yoshioka, 1999).

\section{Retinal astrocyte development}

\subsection{Embryonic Origin}

Retinal vasculature development is closely linked to retinal astrocytes. These specialised glial cells are only found in species that possess a retinal vasculature and provide the foundation for retinal angiogenesis (Stone and Dreher, 1987). In foveate species such as primates, astrocytes are only present in vascular regions and are devoid from avascular areas, as for example the fovea (Gariano et al., 1996; Schnitzer, 1987). During development, retinal astrocytes invade the retina from the optic disc. Retinal astrocytes and optic nerve astrocytes both express the transcription factor PAX2, but the two cell types should be viewed as separate lineages because they have distinct embryonic origins.

Prior to optic fissure closure, PAX2 is expressed in the ventral half of the optic vesicle and optic stalk (Nornes et al., 1990).
As this region invaginates and forms the optic fissure, PAX2 becomes excluded from the retina (Schwarz et al., 2000; Zhao et al., 2012). However, a population of PAX2 and Netrin 1 positive cells remains at the junction between the optic cup and optic stalk which generate the optic disc; a small cuff of cells around the exiting retinal ganglion cell (RGC) axons (Dakubo, 2003; Zhao et al., 2012). The morphogens sonic hedgehog $(\mathrm{SHH})$ and bone morphogenetic protein (BMP) 7 regulate $\mathrm{PAX} 2$ expression and are critical for correct fissure closure and optic disc formation (Morcillo et al., 2006; Sehgal et al., 2009; Yang, 2004; Zhao et al., 2012). At around embryonic day (E) 15 in mice, a subset of cells in the optic disc - immature retinal astrocytes - start expressing platelet derived growth factor receptor alpha (PDGFRA). SHH signalling might contribute to the induction of PDGFRA in these cells because it has been linked to PDGFRA expression and activation in other cells (Dakubo, 2003; Lin et al., 2014; Xie et al., 2001). Regardless, retinal astrocytes are the only astrocyte type in the central nervous system (CNS) that express PDGFRA (Mudhar et al., 1993; Tao and Zhang, 2014) and, therefore, the initiation of PDGFRA expression in retinal astrocytes can be viewed as the beginning of a distinct astrocyte lineage.

\subsection{Retinal invasion}

Immature retinal astrocytes start emerging from the optic disc into the retina (around E18 in mice) as elongated, spindle shaped cells populating the nerve fibre layer, where they eventually take on a stellate morphology as they mature (Fruttiger, 2002). Reciprocal interactions between the neuroretina and astrocytes are important throughout this process (Fig. 3A). RGCs secrete a ligand for PDGFRA, PDGFA, which promotes astrocyte proliferation and migration in a centrifugal fashion across the inner retinal surface towards the retinal periphery, creating a mesh-like network (Fruttiger et al., 1996). In mice, injection of PGDFRA-neutralizing antibody causes underdevelopment of the astrocyte network, whilst overexpression of the PDGFA gene leads to astrocyte hyperplasia (Fruttiger et al., 1996). 

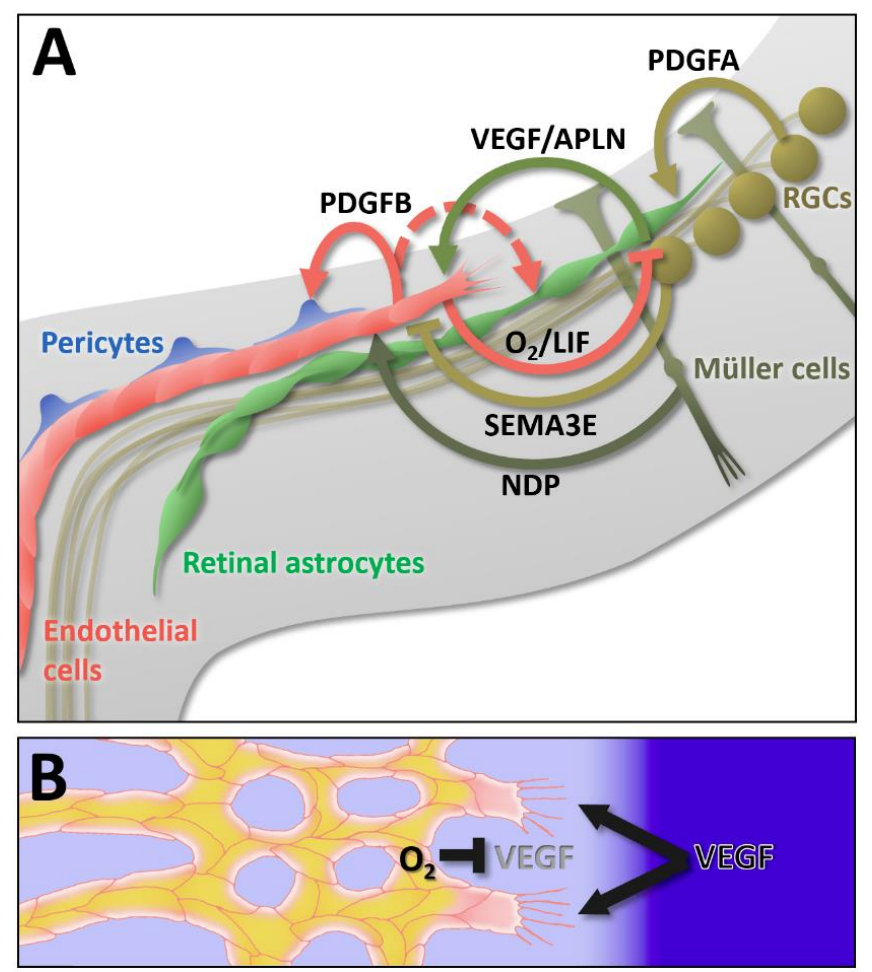

Fig. 3 (A) Cell-cell signalling between RGCs, retinal astrocytes and developing vessels controls the development of retinal vasculature. $P D G F A$ released by RGCs acts on astrocytes to promote proliferation and migration. VEGF and APLN produced by retinal astrocytes and VEGF produced by RGCs and other neural cells act on endothelial cells. In reverse, endothelial cells stabilise retinal astrocytes via LIF. Similarly, oxygen provided by the growing vasculature feeds back on VEGF expression from retinal astrocytes and other neural cells. SEMA3E restricts growth of the developing plexus to the nerve fibre layer. Endothelial derived PDGFB has chemoattractant and mitotic effects on pericytes, but might also influence retinal astrocytes (stippled arrow). (B) Increased VEGF expression in the hypoxic periphery and VEGF suppression in the vascularised centre, creates a hypothetical VEGF gradient (in blue) that guides tip cell migration (vessel perfusion is shown in yellow).

Furthermore, Cre-mediated inactivation of PDGFRA almost completely ablates the retinal astrocyte population and subsequent retinal angiogenesis (Tao and Zhang, 2016).

Immature retinal astrocytes migrate to the inner limiting membrane (ILM), which contains extracellular matrix (ECM) proteins. These proteins can serve as an adhesive substrate, may contain instructive signals for migrating cells and can regulate the availability of soluble growth factors (reviewed by Brown, 2011; S. H. Kim et al., 2011b). The importance of this ECM structure for retinal astrocyte development is illustrated by knock-out mice lacking laminin chains $\alpha 1$, or $\gamma 3$ and $\beta 2$. In these animals, ILM formation is severely disturbed, leading to impaired passage and distribution of retinal astrocytes (Edwards et al., 2010; Gnanaguru et al., 2013; Pinzón-Duarte et al., 2010). Similarly, neural retina specific, genetic deletion of a key enzyme (UDP-glucose 6dehydrogenase, UGDH) for glycosaminoglycan synthesis also disrupts the ILM and abolishes retinal astrocyte migration into the retina; whereas astrocyte specific UGDH deletion does not (Tao and Zhang, 2016). Glycosaminoglycans are polysaccharide chains (such as heparin and heparan sulphate among others) that are covalently linked to proteins (forming proteoglycans) and play a key role in ILM assembly. Thus, the ILM disruption after neural UGDH deletion is probably a direct consequence of impaired glycosaminoglycan synthesis, whereas the failed astrocyte invasion is caused indirectly by the ILM abnormalities (Tao and Zhang, 2016).

It has also been suggested that different PDGFA isoforms are differentially bound by glycosaminoglycans (Andrae et al., 2013), which might be important for establishing PDGFA concentration gradients that guide retinal astrocyte migration towards the periphery. However, retinal astrocytes can migrate towards PDGFA-soaked beads in a retinal explant assay, irrespective of whether the long (heparin binding) or the short (not heparin binding) isoform of PDGFA has been used (Tao and Zhang, 2016). This suggests the existence of a chemoattractive gradient of PDGFA that is independent of extracellular retention motifs in PDGFA. It is possible that retinal astrocytes self-generate such a gradient by acting as a PDGFA sink (e.g. via PDGFA internalisation). Oxygen - delivered by the developing retinal vasculature - might also influence this system as mutant mice that lack the hypoxia-inducible factor 1 alpha (HIF1A) in the peripheral retina display decreased expression of PDGFA and a hypoplastic astrocyte network (Nakamura-Ishizu et al., 2012).

\section{Neural-vascular interactions}

\subsection{Effects of retinal astrocytes on blood vessels}

The expanding network of retinal astrocytes - spreading between the ILM and the nerve fibre layer - is followed by vessels emerging from the optic disc, creating the primary plexus of the developing retinal vasculature. These vessels tightly interact with the template provided by the astrocytes, which express vascular endothelial growth factor A (VEGF) (Fruttiger, 2007; Pierce et al., 1996; Stone et al., 1995; West et al., 2005). VEGF expression stimulates blood vessel growth and is induced by physiological hypoxia in the retina prior to the development of retinal vasculature (Fig. 3). Astrocyte-derived VEGF is, therefore, an obvious candidate to mediate the close relationship between astrocytes and vessels in the retina. However, astrocyte specific deletion of VEGF has only minor effects on the developing vascular plexus (Scott et al., 2010; Weidemann et al., 2010), suggesting that the intimate relationship between retinal astrocytes and endothelial cells in the developing retinal vasculature is also based on other factors.

Nevertheless, retinal astrocytes are crucial for vascular development, as illustrated by astrocyte-specific deletion of PDGFRA (see section 2.2), which prevents astrocyte invasion into the retina. Consequently, the development of blood vessels does not occur, except for a few vascular sprouts which closely align to stray astrocytes that fail to be genetically inactivated (Tao \& Zhang, 2016). The close proximity to astrocytes, required by endothelial cells, indicates that the essential role of astrocytes in angiogenesis might be based on providing a physical growth substrate for 
the vessels. Indeed, astrocytes have been shown to express fibronectin - an ECM protein - ahead of growing vasculature (Uemura et al., 2006). Fibronectin and heparan sulphate synergistically bind VEGF to guide endothelial tip cell migration, and their genetic deletion impairs vascular migration (Stenzel et al., 2011). Furthermore, endothelial filopodial protrusions closely align to astrocytes via adhesions formed between fibronectin and $\alpha 5 \beta 1$ integrin (Stenzel et al., 2011; Uemura et al., 2006). R-cadherinmediated cell to cell adhesions formed between astrocytes and the endothelial filopodia (Dorrell et al., 2002; Gerhardt et al., 2003) have also been shown to stabilise vessel sprouts. However, when factors such as astrocyte derived fibronectin and heparan sulphate are ablated together (Stenzel et al., 2011), or when R-cadherin is blocked (Dorrell et al., 2002), the resulting impairment in growth of the primary vascular plexus is not as dramatic as the phenotype seen when the astrocyte population is ablated from the developing retina (Tao and Zhang, 2016). This suggests that other, as yet unknown, but essential factors for retinal vasculature development are provided by the astrocyte template.

\subsection{Effects of blood vessels on retinal astrocytes}

In addition to the effects retinal astrocytes have on blood vessels, a reverse interaction also occurs, where the developing vessels impact on retinal astrocyte development by promoting their differentiation. In response to the arriving blood vessels, the astrocytes upregulate glial fibrillary acidic protein (GFAP), cease to proliferate and downregulate VEGF expression (West et al., 2005). Astrocytes in contact with vessels also downregulate the orphan nuclear receptor tailless (TLX), which is strongly expressed in more peripheral, immature astrocytes, and is required for their proliferation and migration into the retina (Miyawaki et al., 2004; Uemura et al., 2006). Suppressing vessel growth with a VEGF antagonist (aflibercept, also known as VEGF-Trap) prevents upregulation of GFAP and downregulation of VEGF, resulting in a denser retinal astrocyte network. This demonstrates the negative feedback effect of vessels on retinal astrocytes (Uemura et al., 2006). Oxygen, supplied by the developing vessel network, appears to be a factor that mediates the effects of vessels on astrocytes, since oxygen can regulate GFAP and VEGF expression in retinal astrocytes (West et al., 2005). Furthermore, deleting hypoxia inducible factor 2A (HIF2A) specifically in retinal astrocytes accelerates their differentiation and lowers their numbers, leading to reduced retinal vasculature development (Duan et al., 2014).

Other factors mediating crosstalk between blood vessels and retinal astrocytes are leukaemia inhibitory factor (LIF) and apelin (APLN). Astrocytes secrete APLN, which stimulates production of LIF from endothelial cells via the endothelial receptor for apelin (APLNR, also known as APJ) (Sakimoto et al., 2012). The LIF receptor (LIFR) is expressed by the surrounding retinal astrocytes awaiting vascularisation. LIF then induces astrocytes to differentiate into a more mature state and thereby acts as an inhibitor of retinal astrocyte proliferation (Kubota et al., 2008). This feedback loop stabilises both astrocytes and blood vessels, since the vessels depend on the retinal astrocytes. LIF and APLNR knock-out mice both display a denser astrocyte and vessel network (Kubota et al., 2008; Sakimoto et al., 2012), demonstrating that the two networks are intrinsically linked (Fig. 3A).

Another connection between retinal astrocytes and blood vessels could involve PDGFB, which is expressed by endothelial cells and normally targets developing pericytes expressing PDGFRB (see section 5.3). However, PDGFB can also activate PDGFRA on retinal astrocytes (Andrae et al., 2008), and endothelial cells have therefore the potential to not only stimulate pericytes, but also to promote retinal astrocyte proliferation (stippled arrow in Fig. 3A). Although this interaction has so far not been experimentally verified, it further highlights the complexity of the feedback interactions that can occur between retinal astrocytes and blood vessels.

\subsection{Role of RGCs in regulating retinal vasculature development}

Although the presence of retinal astrocytes is indispensable for normal retinal vasculature development, neurons in the retina also influence the growing retinal vasculature. Given that neurons have a high metabolic requirement, they are prone to experience hypoxia, stabilise HIF1A and consequently express VEGF (Semenza, 2011). VEGF produced by neurons and Müller cells is the likely reason why astrocyte specific VEGF deletion causes no impairment in the retinal vasculature observed (Scott et al., 2010; Weidemann et al., 2010, see chapter 4.2). In fact, RGCs are crucial for normal retinal vasculature development, since in mutant mouse strains that lack RGCs, the primary plexus fails to develop, despite the presence of retinal astrocytes (Edwards et al., 2012; Ghinia et al., 2016; Sapieha et al., 2008). The importance of RGCs lies in their ability to sense hypoxia in the developing retina. Succinate - an intermediate of the Krebs cycle - accumulates in the hypoxic retina, and its receptor, G protein-coupled receptor-91 (GPR91), is primarily expressed in RGCs (Sapieha et al., 2008). Through GPR91, RGCs sense changes in the neuronal metabolic demand prior to HIF1A stabilisation, and regulate the production of angiogenic growth factors so that vascular supply meets the demands of the neuroretina. This is further supported by experiments where knockdown of retinal GPR91 resulted in reduced retinal vascularisation (Sapieha et al., 2008).

G protein-coupled receptor coagulation factor-like (F2RL1) has also been shown to be highly expressed in RGCs and promotes retinal vascularisation during development through its regulation of VEGF (Joyal et al., 2014). Furthermore, RGCS also produce the anti-angiogenic semaphorin 3E (SEMA3E), which prevents misdirection of the developing vasculature and limits the growth of the primary plexus to the nerve fibre layer (Fig. 3A) (Fukushima et al., 2011; J. Kim et al., 2011a, see section 4.2). Moreover, VEGF receptor 2 (VEGFR2) is highly expressed in the neuroretina during the first week after birth and mediates receptor mediated endocytosis of VEGF. Neurone-specific genetic deletion of VEGFR2 prevents VEGF endocytosis by 
neuronal cells, leading to an excess of VEGF in the extracellular space. This leads to a delay in radial extension of the primary plexus and premature initiation of deeper plexus development, demonstrating that retinal neurons titrate VEGF levels to co-ordinate the development of the retinal vasculature (Okabe et al.,2014).

\section{Mechanisms of sprouting angiogenesis}

In the expanding primary plexus, angiogenesis can be particularly well observed. At the leading edge, short vessel sprouts expand into the avascular retina and then fuse with neighbouring sprouts, creating perfused loops. A reiterative process of loop formation creates a primitive plexus, which subsequently remodels into a hierarchical network (Fig. 2A). The emergence of such a complex structure from just two cell types - endothelial cells and mural cells - poses many conceptual challenges: How is the requirement for a continuous, lumenised endothelium compatible with directional migration of endothelial cells towards hypoxic parenchyma? Or how can individual endothelial cells "know" their position within the network to display specific behaviours; for example, at the growing plexus edge or in differentiating arteries or veins? In recent years, significant progress has been made towards a better understanding of the integrated cellular and molecular mechanisms that underpin some of the basic morphogenetic functionalities required for blood vessel development. In this section, we broadly discuss aspects that are relevant to the retinal vasculature; however, other reviews cover these topics more comprehensively (Jin et al., 2014; Marcelo et al., 2013; Potente et al., 2011; Potente and Carmeliet, 2017).

\subsection{The endothelial tip-stalk machinery}

A fundamental morphogenetic module in vascular network formation is the extension of vessel sprouts. This process requires differential behaviour of endothelial cells, depending on their location. Cells at the tip of the sprout are more motile and less proliferative in comparison to endothelial cells in the stalk (Gerhardt et al., 2003). It has been proposed that tip cells guide the direction of growth, sensing gradients of VEGF and other angiogenic factors (Adams and Eichmann, 2010; Carmeliet and Tessier-Lavigne, 2005; Larrivée et al., 2009). In contrast, cells in the stalk proliferate and form the vessel lumen, sustaining sprout extension and perfusion (Fig. 4A). Endothelial tip cells display a different transcriptional profile to the trailing cells in the stalk (del Toro et al., 2010; Strasser et al., 2010), which is the basis of their differential behaviour. Furthermore, endothelial cells in the tip state supress the tip phenotype in adjacent endothelial cells via the Notch signalling pathway. Because individual cells can flip dynamically between tip and stalk phenotypes, a dynamic competition for the tip position ensues (Jakobsson et al., 2010).

The Notch ligand Delta like 4 (DLL4) is central to the tip phenotype and can be viewed as a toggle switch that sets the tip/stalk state. It is expressed strongly in the tip state, activating NOTCH1 in adjacent cells, where it supresses DLL4 transcription (Benedito et al., 2009). Experimental blocking

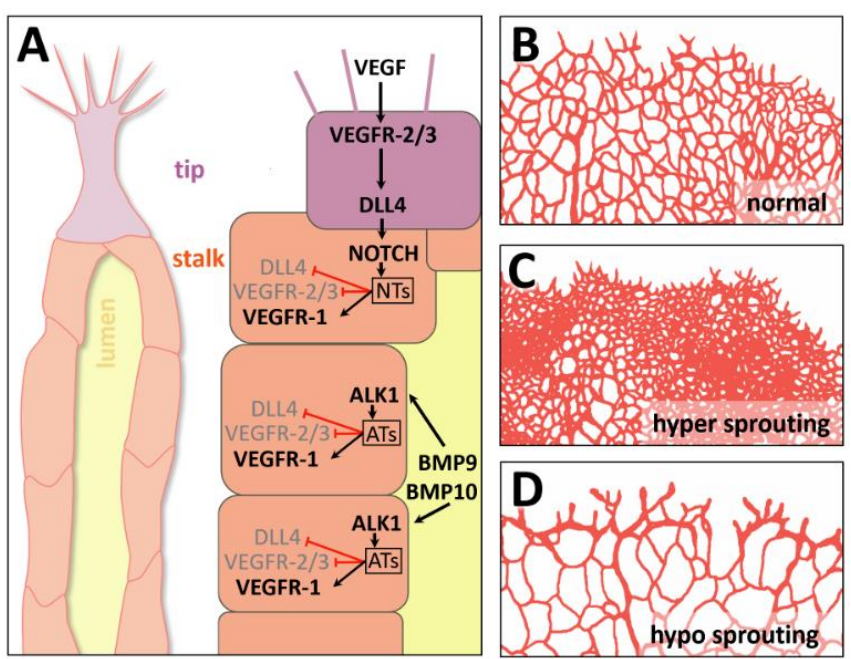

of DLL4/NOTCH1 signalling (chemically or via gene deletion)

Fig. 4 (A) The tip/stalk phenotype in sprouting endothelial cells is mediated via VEGF, inducing VEGFR2/3 and DLL4 at the tip. Activated Notch acts via Notch-targeted transcription factors (NTs) by supressing DLL4 and VEGFR2/3, and inducing VEGFR1. This reduces sensitivity to VEGF and stabilises the stalk phenotype. $B M P 9 / 10$ in the plasma acts via ALK1 on similar downstream targets (ATs) as Notch, and further promotes the stalk phenotype. Vascular hyper-sprouting (C) occurs when Notch or ALK1 signalling is blocked (favouring the tip phenotype). In contrast, hypo-sprouting (D) can be induced by excessive BMP9. It is also found in mice with loss of function mutations in the TGFB1 and WNT signalling pathways.

reduces this inhibition of neighbouring cells, allowing more endothelial cells to enter the tip state, leading to increased branching in the primary plexus of the retinal vasculature (Hellström et al., 2007; Lobov et al., 2007; Suchting et al., 2007) (Fig. 4A, C). The Notch mediated tip/stalk toggle mechanism is tightly integrated with VEGF signalling (reviewed by Blanco and Gerhardt, 2013; Simons et al., 2016; Thurston and Kitajewski, 2008). On the one hand, activation of VEGFR2 promotes the transcription of DLL4, and hence the tip state. On the other, endothelial cells in the tip state are more sensitive to VEGF than endothelial cells in the stalk state, because NOTCH1 activation downregulates the expression of VEGFR2/3 and upregulates VEGFR1 (Benedito et al., 2012; Siekmann et al., 2008; Zarkada et al., 2015). VEGFR1 can act as a VEGF antagonist due to its decoy receptor activity (Kappas et al., 2008; Kendall and Thomas, 1993). Therefore, this mechanism dynamically favours the tip state at the leading edge of the growing plexus (where VEGF concentration is most likely highest) based on the position of cells, rather than the identity of cells.

Tip cell chemotaxis towards a VEGF source requires a gradient of VEGF levels (Bentley et al., 2009; Blanco and Gerhardt, 2013). Although such a gradient has never been formally demonstrated in the retina, its existence is likely because VEGF mRNA expression is higher in the peripheral, not yet vascularised - and therefore hypoxic - retina, compared to the central, perfused retina, where oxygen supplied by the developing vessels suppresses VEGF expression (West et al., 2005). Furthermore, experimental manipulations that disturb this VEGF gradient - for instance intraocular injection of either VEGF or VEGF antagonist 
(aflibercept) - cause filopodia to disappear from the leading vascular edge, and consequently vascular plexus expansion is reduced (Gerhardt et al., 2003; Ubezio et al., 2016). Moreover, extracellular VEGF distribution and availability is regulated by interactions with components of the extracellular milieu, such as fibronectin or glycosaminoglycans, via heparin binding domains in alternatively spliced exons of VEGF, which can influence retinal vascular development (Domigan and Iruela-Arispe, 2014; Gerhardt et al., 2003; Rocha et al., 2014; Stalmans et al., 2002; Vempati et al., 2011; Wijelath et al., 2006).

It has been widely assumed that filopodia on endothelial tip cells are used for sensing the distribution of angiogenic factors; analogous to filopodia on axonal growth cones sensing guidance cues. This is based on the fact that filopodia extend in the direction of vascular growth and become misdirected and shorter in response to disturbances of VEGF distribution (De Smet et al., 2009; Gerhardt et al., 2003). However, these observations do not prove a causal relationship between filopodia and tip cell guidance. In fact, more recent experiments in zebrafish from Gerhardt et al. have shown that, surprisingly, filopodia are dispensable for endothelial tip cell guidance. In these experiments, the growth and patterning of intersegmental vessels were not disturbed by abolishing filopodia (using a low dose of Latrunculin B, which prevents F-actin polymerisation). Nevertheless, tip cells were still able to create lamellipodia, which, under these circumstances, might act as mediators of guided angiogenesis (Phng et al., 2013; Wacker et al., 2014).

Although the VEGF/Notch signalling, described above, can execute the binary decision making between the tip and stalk state at the very tip of the sprout, it is less obvious how this mechanism can be used to supress the tip state in more proximal stalk cells that are not in direct contact with DLL4 expressing tip cells. Here, the recent discovery of a novel function of the TGF beta superfamily signalling pathway in angiogenesis can provide some explanation. Blocking BMP9/BMP10 signalling, or genetic deletion of ALK1 (which is part of the BMP receptor complex), increases the number of tip cells and leads to the same hyperbranching phenotype as Notch signalling inhibition in the retinal vasculature (David et al., 2008, 2007; Larrivée et al., 2012; Ricard et al., 2012; Tual-Chalot et al., 2014); demonstrating that BMP9/10 ALK1 signalling normally suppresses the tip state in endothelial cells. In fact, ALK1 activates similar downstream target genes as NOTCH1 (such as HES1, HEY1, HEY2, JAG1, VEGFR1), which promote the stalk state (Larrivée et al., 2012; Moya et al., 2012). Intriguingly, BMP9 and BMP10 are present at high levels in plasma, suggesting an elegant stabilisation mechanism for the more proximal, perfused portion of the sprout, where endothelial cells are directly exposed to plasma (Fig. 4A).

\subsection{Modulators of the endothelial tip-stalk state}

The integration of the Notch, VEGF and ALK1 signalling pathways provides the basic conceptual machinery for maintaining a continuous endothelium in a lumenised, growing stalk, whilst supporting tip cell chemotaxis and invasion into the parenchyma. In addition, there are many other factors and pathways that can modulate this signalling network; some of which directly modulate Notch activity. For instance, JAG1 (a weak Notch ligand) acts as a competitive DLL4 antagonist (Benedito et al., 2009). Further regulation is found at the level of the Notch downstream effector, the Notch intracellular domain (NICD), which is destabilised by the Notch-regulated ankyrin repeat protein (NRARP) to prevent sustained signalling (Phng et al., 2009). Moreover, sirtuin 1 deacetylase (SIRT1), which also destabilises NICD, is a further negative regulator of the tip state (Guarani et al., 2011). In addition, DLL4 expression can be suppressed by the semaphorin SEMA3E, which is secreted in the retina by RGCs (as mentioned above in section 3.3) (Fukushima et al., 2011; J. Kim et al., 2011a). Interestingly, the receptor for SEMA3E, plexin D1 (PLXND1), is induced by VEGF (Fukushima et al., 2011; J. Kim et al., 2011a), which means that this tip state suppression mechanism is most active in endothelial cells at the leading plexus edge, where VEGF levels are highest. Several other class-3 semaphorins can also suppress the tip state and inhibit endothelial cell migration, such as SEMA3A (Ochsenbein et al., 2016), SEMA3C (Yang et al., 2015) and SEMA3D (Aghajanian et al., 2014; Hamm et al., 2016). At first sight, it might appear counterintuitive to have so many negative regulators of the tip state. However, it is important to put brakes on the tip state, otherwise sprouts would branch excessively and produce too dense a plexus.

That being said, there are also positive regulators of the tip state. For example, the enzyme phosphofructokinase2/fructose-2,6-bisphosphatase 3 (PFKFB3) promotes the tip phenotype by stimulating glycolysis. PFKFB3 synthesizes fructose-2,6-bisphosphate, which is an allosteric activator of 6-phosphofructo-1-kinase (PFK1), the rate limiting enzyme of glycolysis. Endothelial cells rely heavily on glycolysis, in particular when they are migrating. Genetic deletion or pharmacological inhibition of PFKFB3 consequently reduces angiogenic sprouting by impairing tip cell activity. Conversely, endothelial cells that overexpress PFKFB3 can outcompete wild type cells for the tip cell position (De Bock et al., 2013; Schoors et al., 2014). Remarkably, this competitive advantage is maintained even when these cells are handicapped by introducing NICD overexpression (mimicking a pro-stalk Notch signal), suggesting that reduced glycolysis in stalk cells may be a key outcome of Notch signalling (De Bock et al., 2013).

Another example of a positive contributor to the tip state is neuropilin 1 (NRP1). Genetic deletion of NRP1 in endothelial cells reduces sprouting activity at the leading edge of the primary plexus, resulting in thickened sprouts, reduced branching and slower plexus expansion (Aspalter et al., 2015) (Fig. 4D). Furthermore, in mosaic experiments (where NRP1 has been deleted only in some but not all endothelial cells), wild type cells outcompete NRP1 knock-out cells for the tip position (Aspalter et al., 2015; Fantin et al., 2013), implicating NRP1 as a promoter of the tip state. NRP1 lossof-function phenotypes have long been attributed to impaired VEGF or semaphorin signalling because of NRP1's well known function as a VEGFR2 or PLXND2 co-receptor (Gu et al., 2003; Kawasaki et al., 1999). However, mice with a 
mutated form of NRP1 that cannot bind VEGF, develop normally (Gelfand et al., 2014). In addition, semaphorins tend to suppress the tip state (as mentioned above), rather than promote it, which suggests that NRP1 contributes to tip cell signalling in the context of an alternative pathway.

Indeed, besides VEGF and semaphorins, NRP1 can also bind transforming growth factor beta-1 (TGFB1) (Glinka and Prud'homme, 2008) and has been shown to regulate TGFB1 mediated sprouting angiogenesis during CNS development (Hirota et al., 2015). Endothelial specific TGFB receptor 2 (TGFBR2) knock-out mice show a hypobranching phenotype in the primary plexus of the retinal vasculature very similar to NRP1 knock-out mice (Allinson et al., 2012). Moreover, the same phenotype is caused by retinal astrocyte specific deletion of integrin $\alpha$ v or $\beta 8$ (ITAGV or ITGB8), which has been linked to deficient integrin-mediated TGFB activation (Arnold et al., 2012; Hirota et al., 2011; McCarty, 2009). In summary, there are multiple lines of evidence linking TGFB1 to a function that supports the tip state during retinal vasculature development. Furthermore, it is intriguing that TGFB1 and BMP9/10, which signal through two separate arms of the TGFB superfamily pathway (Pardali et al., 2010), appear to have opposite effects on the tip state. However, the molecular details of this, and how exactly NRP1 influences the balance between the two signalling arms, are yet to be fully elucidated.

The characteristic sprout thickening and reduced branching at the growing edge of the primary plexus is not only found in NRP1, TGFRB2, ITGAV and ITGB8 knock-out mice, but it is also displayed by mice lacking Norrin (also known as Norrie disease protein, NDP) (Xu et al., 2004). This factor is secreted by Müller cells and can signal via the canonical WNT signalling pathway (Xu et al., 2004). Endothelial cells in the retinal vasculature express a receptor complex, consisting of FZD4, LRP5 and TSPAN12, that can bind Norrin with high affinity. Deleting any one of the three genes that make up this receptor complex phenocopies Norrin knock-out mice, which demonstrates that all three components are needed for effective signalling. These knock-out phenotypes in the developing retinal vasculature imply that Norrin signalling normally promotes the tip state in endothelial cells, but the downstream signalling circuitry is not fully known. One potential link could be the transcription factor SOX17, which is induced by Norrin (Ye et al., 2009), repressed by Notch signalling, and contributes to angiogenic and tip cell functions (Lee et al., 2014; Ye et al., 2009). However, although endothelial specific SOX17 deletion in mice does lead to reduced branching in the retinal vasculature primary plexus, it does not cause the typical sprout thickening seen in Norrin signalling knock-out mice (Lee et al., 2014), suggesting involvement of other factors. Thus, despite the strikingly similar retinal vasculature phenotypes caused by defective TGFB1 and Norrin signalling, it so far not clear where these two pathways intersect.

In humans, gene mutations in the Norrin signalling pathway have been linked to familial exudative vitreoretinopathy (FEVR) and account for 4 out of the so far 5 identified FEVR genes (NDP, FZD4, LRP5, TSPAN12), causing roughly half of all FEVR cases (reviewed by Gilmour, 2014). The hallmark clinical feature of FEVR is incomplete vascularisation of the retinal periphery during development. Correspondingly in mice, Norrin signalling mutations delay the expansion of the primary plexus. Whether and how the tip-stalk balance is affected in FEVR is not yet clear though, because the human retina is not as easily accessible to cellular imaging analysis as the mouse retina. Furthermore, the gene mutations in the $50 \%$ of FEVR cases that are not based on Norrin signalling defects still need to be identified. In this context, it will be interesting to see whether the phenotype similarities between Norrin and TGFB signalling defects in mice (described above) bear out in humans via the discovery of novel FEVR genes in the TGFB signalling pathway.

\subsection{Deeper plexus development}

The tip/stalk concept, which explains very successfully a specific behaviour of endothelial cells, initially emerged from studying primary plexus development in the mouse retinal vasculature and, therefore, the roles of many genes are well characterised in primary plexus development. However, other aspects of retinal vascularisation - such as deeper plexus development, network remodelling and artery/vein differentiation - are less studied and, therefore, less well understood. Nevertheless, many of the signalling pathways acting in the tip/stalk machinery during primary plexus development also have a role in other vascular development processes. For instance, there is a strong overlap between primary and deeper plexus development in mice. Deleting the above-mentioned genes in the TGFB or Norrin signalling pathways (Norrin, FZD4, LRP5, TSPAN12, TGFBR2, NRP1, ITGAV or ITGB8) not only stunts the growth of the primary plexus, but also negatively impacts on the development of the deeper plexus. However, the severity of the phenotype in the two networks is different. Whilst the primary plexus displays thickened sprouts and reduced branching, overall network formation still proceeds, albeit at a slower rate. In contrast, deeper network development completely fails (Allinson et al., 2012; Hirota et al., 2015, 2011; Junge et al., 2009; Xu et al., 2004; Ye et al., 2009) and only produces thick, club-like stumps that project from the primary plexus into the retina and do not branch sideways (Fig. 5).

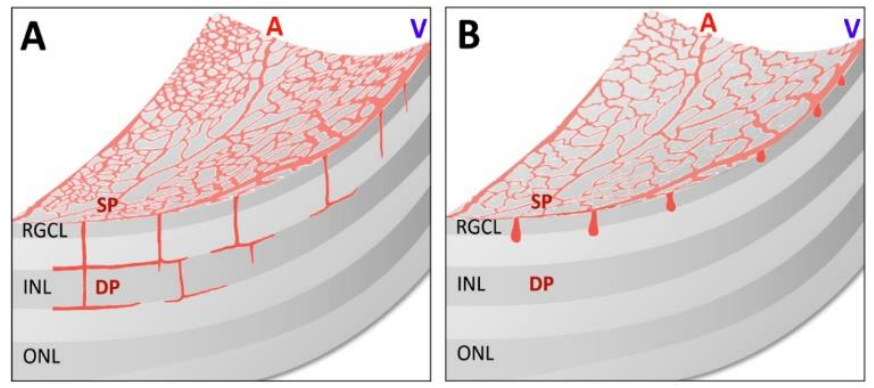

Fig. 5 (A) Deeper plexus development is initiated from veins in the superficial plexus. (B) Loss of function mutations in the TGFB1 and WNT signalling pathway stunts deeper plexus development and leads to the formation of vascular clumps in the superficial layers of the retina. RGCL: retinal ganglion cell layer, INL: inner nuclear layer, ONL: outer nuclear layer, SP: superficial plexus, DP: deeper plexus. 
It is tempting to speculate that Norrin and TGFB signalling might play a specific role in guiding vessel sprouts into the deeper layers of the retina. Indeed, the fact that Norrin is produced by Müller cells, along which the initial sprouts extend into the retina, raises the possibility that it may act as an angiogenic guidance cue. However, this is unlikely because ectopic expression of Norrin from the lens in transgenic mice can rescue the Norrin knock-out phenotype (Ohlmann et al., 2005). Furthermore, endothelial cells that lack FZD4 - one of the five FEVR genes - are able to participate in the deeper plexus vascularisation in mosaic animals (where not all endothelial cells lack FZD4), suggesting that neighbouring wild type endothelial cells can largely correct the vascular migration defects of FZD4 knockout endothelial cells (Wang et al., 2012). This may be explained by the tip/stalk model, which predicts that in mosaic situations, wild type cells are selected for the tip position and are capable of driving angiogenesis. Since Norrin (and TGFB) signalling promote the tip state (as mentioned above), a complete lack of tip cells can explain the clumping phenotype seen in the full knock-outs.

Why the deeper plexus is more dramatically affected than the primary plexus is not established and open to speculation. However, it is unlikely that the difference in phenotype severity is caused by a unique property of the deeper retina, because a similar phenomenon is also observed during vascular development in the brain. Here, loss of function mutations in the TGFB signalling pathway (Arnold et al., 2014; McCarty, 2009) or in the Norrin/WNT signalling pathway (Kuhnert et al., 2010; Zhou and Nathans, 2014) cause pronounced clumps in vessels that penetrate the brain (topologically corresponding to the retinal deeper plexus), whereas vessels at the brain surface (topologically corresponding to the retinal primary plexus) are normal. Thus, it appears that Norrin and TGFB signalling defects still permit the emergence of some tip cells during the development of the retinal primary and the brain superficial plexus, whereas this appears not to happen in the vessels penetrating the retina or the brain. Perhaps the fact that the development of these penetrating vessels must be initiated from already quiescent and differentiated vessels (lacking tip cells at this stage) plays a role here.

The question remains then; what factors guide angiogenesis towards the outer retina? Not surprisingly, the strongest candidate for guiding deeper plexus development so far is VEGF. Indeed, genetic deletion of VEGF - specifically from amacrine and horizontal cells - impairs deeper plexus formation (Usui et al., 2015). The authors of this study show that physiological hypoxia drives VEGF expression in amacrine cells, which is needed to establish a layer of vessels within the deeper plexus that are tightly associated with this cell type. As mentioned earlier in section 3.3, VEGF bioactivity is further modulated by VEGFR2 expressing neurons, endocytosing VEGF and acting as a VEGF sink. During retinal development, neuronal VEGFR2 expression is downregulated at around P7, allowing for a build-up of VEGF and triggering deeper plexus development (Okabe et al., 2014). However, little is currently known about deeper plexus development beyond the role of VEGF, and it remains to be established whether there are any other factors needed to drive and/or guide angiogenesis; particularly with regards to how horizontally or perpendicularly oriented cell populations (such as amacrine, horizontal and Müller cells) contribute to the patterning of this network.

Correct retinal vascularisation requires not only the stimulation of angiogenesis, but also the presence of negative control mechanisms. For example, the expression of VEGFR1 by retinal myeloid cells in the deeper retinal layers - upon stimulation by WNT signalling - antagonises VEGF and angiogenic branching during deeper plexus development (Stefater et al., 2011). Furthermore, photoreceptors and the retinal pigment epithelium (RPE) also express soluble VEGFR1 (Luo et al., 2013), meaning vessels do not normally grow beyond the outer plexiform layer, and the photoreceptor layer remains completely avascular. Moreover, SEMA3F, which has also antiangiogenic properties, is expressed in the same location (Buehler et al., 2013). Interestingly, the anti-angiogenic barrier of the outer retina is overcome in mice that lack the very low density lipoprotein receptor (VLDLR). In these animals, the deeper plexus vessels continue to grow until they reach the subretinal space. It has been shown that this is due to a deficiency in energy substrates in the photoreceptors, which leads to HIF1A stabilisation and VEGF upregulation (Joyal et al., 2016), illustrating that the avascularity of the outer retina can be breached with sufficiently strong stimuli. This mechanism might also be relevant in human disease, such as macular telangiectasia type 2 or age related macular degeneration, where retinal angiomatous proliferation (RAP) or choroidal neovascularisation (CNV) can lead to vessels invading the photoreceptor layer (Charbel Issa et al., 2013; Donati et al., 2005; Dorrell et al., 2009).

\section{Network remodelling and maturation}

Angiogenic sprout and loop formation generate primitive networks, which are subsequently remodelled into structured, hierarchical vascular trees. This remodelling process is governed by two opposing forces: vessel regression and vessel stabilisation (reviewed by Korn and Augustin, 2015). Lack of perfusion, endothelial cell migration and endothelial cell apoptosis are all destabilising factors, whereas perfusion, endothelial-mural cell interactions and vessel maturity are important contributors towards vessel stabilisation. Newly formed, immature capillaries are unstable and can regress quickly; whilst larger, more mature vessels are better at withstanding destabilising forces (Fig. 6A). However, what exactly constitutes a mature or an immature vessel is not well specified and depends on many factors. An easier distinction can be made between the angiogenic and quiescent state of vessels, with the former being characterised by the presence of endothelial tip and stalk cells in the angiogenic sprout; and the latter containing non-proliferative endothelial cells in stable, more proximal vessels sections (referred to by some authors as 'phalanx cells'). However, it should be recognised that this quiescent 
category comprises a wide spectrum of maturation stages influencing vessel stability.
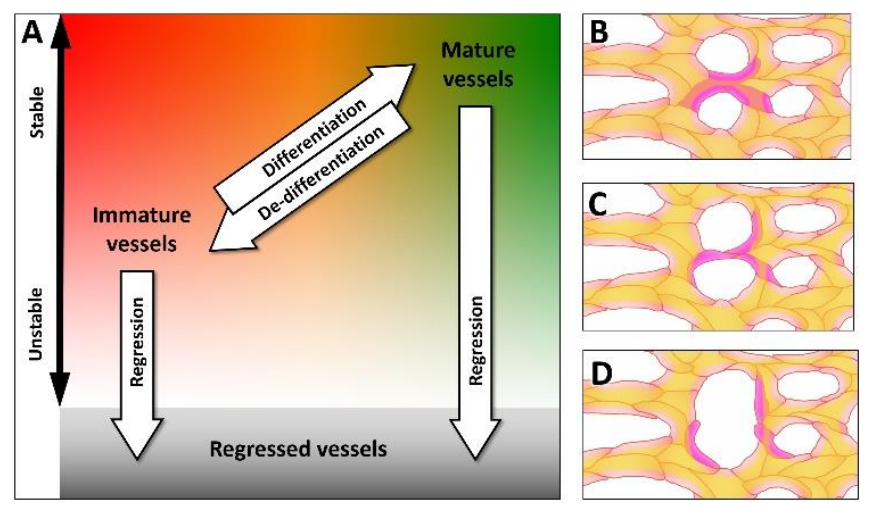

Fig. 6 (A) Newly formed vessels are stabilised by differentiating into a quiescent and more mature state. However, angiogenic and quiescent vessels can both become unstable and regress. (B-D) One mechanism of vascular regression can occur via lateral migration of endothelial cells into adjacent branches (purple cells), which leads to the pruning of the vessel. The perfused vascular lumen is indicated in yellow.

\subsection{Vessel pruning through endothelial cell migration}

At the growing edge of the developing primary plexus, vessels are highly proliferative (Ehling et al., 2013), whereas the region towards the centre of the retina shows little proliferation (except in the main radial veins) and is dominated by remodelling of the newly generated primitive plexus (Fig. 2A). Although vessels are quiescent in this remodelling region, they are still unstable, and either differentiate into more mature vessels or are pruned. The regression of these vessels in the remodelling network is largely driven by the migration of endothelial cells into neighbouring vessel branches, leading to selective pruning of individual capillaries, and strengthening of adjacent ones (Fig. 6B-D). This type of remodelling has been observed in chick embryos during early development of the extraembryonic vasculature (le Noble et al., 2004). Other studies in zebrafish and mouse yolk sac have shown that endothelial cells can undergo lateral migration (movement along the vessel without detachment from the basement membrane) during pruning of functionally redundant vessels, in order to establish a more efficient network topology (Chen et al., 2012b; Kochhan et al., 2013; Udan et al., 2013). The contribution of this process to retinal vasculature remodelling has so far not been directly observed in vivo, but there is good indirect evidence (based on mapping the polarity of individual endothelial cells) suggesting that primary plexus remodelling is heavily based on endothelial cell migration (Franco et al., 2015).

Two key factors controlling lateral endothelial cell migration within the remodelling plexus are blood perfusion (the presence of blood in the capillaries) and shear stress (the mechanical force exerted by the blood against the capillary wall). This has been shown in zebrafish brain, where a reduction in blood flow is cable of initiating pruning; whilst forcing blood through a vessel is preventative (Chen et al., 2012b). Similarly, in the retinal vasculature, high flow leads to a change in endothelial cell polarity, causing endothelial cell migration from low-flow into high-flow segments. This leads to increased stability of the high-flow, and regression of the low-flow vessels (Franco et al., 2015). The influence of blood flow has also been demonstrated by intravitreal injection of the potent vasoconstrictor angiotensin II in developing mice (at P9), which causes widespread nonperfusion and regression in the retinal vasculature (Lobov et al., 2011). Shear stress also induces the transcription of Krüppel-like factor 2 (KLF2), which is a pivotal component of the endothelial transcriptional response to blood flow (reviewed by Novodvorsky and Chico, 2014). KLF2 stabilises flow via the induction of vasodilators (endothelial nitric oxide synthase and C-natriuretic peptide) and the repression of vasoconstrictors (endothelin-1 and angiotensinconverting enzyme); thereby promoting vessel dilation and perfusion (Dekker et al., 2005).

\subsection{Apoptosis driven vessel regression}

Along with lateral migration, network remodelling can also be driven by apoptosis in specific endothelial cells, leading to selective vessel regression. Evidence of this process in the developing retinal vasculature comes from a study demonstrating the presence of CD18 positive T-lymphocytes in remodelling regions of the retinal vasculature. Furthermore, treatment with antibodies against CD18 (a leucocyte adhesion molecule) or Fas ligand (a type-II transmembrane protein of the TNF family, which induces apoptosis through the binding of its receptor) increased network density, implying that T-lymphocyte induced apoptosis in endothelial cells contributes to network remodelling (Ishida et al., 2003). However, a more recent study found that apoptosis events are relatively rare during primary plexus remodelling, suggesting that they do not play a major role in the pruning of capillaries during early retinal vasculature development (Franco et al., 2015). Furthermore, in mice lacking both apoptosis effector proteins BAK and BAX in endothelial cells, remodelling of the primary plexus is normal, confirming that lateral endothelial cell migration is the main driver of vessel pruning in this system (Watson et al., 2016). In wild type mice, a low level of apoptosis can still be detected, predominately around arteries at P6. This could be linked to the high oxygen and low VEGF levels in the immediate vicinity of arteries (Claxton and Fruttiger, 2003), and the formation of the capillary free spaces around them (Fig. 2A). Remarkably, however, BAK/BAX knock-out mice appear to have normal capillary free spaces, despite complete suppression of endothelial apoptosis (Watson et al., 2016), indicating that capillary pruning around arteries is also primarily mediated via lateral migration.

In contrast, regression of the hyaloid vasculature is markedly delayed in BAK/BAX knock-out mice, demonstrating that endothelial cell apoptosis can be an important end-point in vessel regression (Watson et al., 2016). Apoptosis seems to be particularly relevant when an entire network is removed, for example during hyaloid vasculature or pupillary membrane regression. Here, macrophages can induce localised endothelial cell death via the secretion of WNT7B, which causes flow stasis and subsequently endothelial cell 
apoptosis along the entire vessel (Lobov et al., 2005). This process is coordinated by angiopoietin 2 (ANG2) (produced by pericytes), which not only stimulates WNT7B secretion from macrophages, but also predisposes endothelial cells to apoptosis (Rao et al., 2007).

Hyaloid regression is also delayed in mouse pups that are reared in the dark or lack the melanopsin gene (OPN4). Such mice display reduced apoptosis in hyaloid vessels and primary plexus overgrowth, caused by raised VEGF levels in the eyes (Rao et al., 2013). How exactly light modulates VEGF levels in this system is not yet known, but it is clear that neurons in the retina play a major role in hyaloid regression. Evidence for this comes from mice with a neuron specific VEGFR2 ablation (mentioned previously in section 3.3 and 4.3, Okabe et al., 2014). In these animals, VEGF sequestration by neurons (via VEGFR2 endocytosis) is reduced, and the resulting increase in vitreal VEGF antagonises apoptosis in the hyaloid. This phenotype can be corrected by simultaneously deleting VEGF in neurons, which brings VEGF back down to normal levels (Yoshikawa et al., 2016).

Irrespective of whether vessels regress via lateral migration or apoptosis, they leave behind an empty, collapsed basement membrane sleeve (Ehling et al., 2013; el-Hifnawi et al., 1994; Scott et al., 2010). These "string" or "ghost vessels" (as they are sometimes referred to) are commonly used as a readout of ongoing vessel regression. In developing tissues they are present only transiently (Ashton and Pedler, 1962; Scott et al., 2010), whereas in adults, they appear to persist for much longer - even at the capillary level (Brown and Thore, 2011; Powner et al., 2016) - possibly due to a different basement membrane composition in fully matured blood vessels.

\subsection{Vessel maturation}

Vascular regression is antagonised by vessel maturation; a process involving multiple interactions between mural cells (pericytes and smooth muscle cells) and endothelial cells (reviewed by Armulik et al., 2011 and Winkler et al., 2011). One of the first steps in this relationship is the recruitment of mural cells to nascent endothelial sprouts. Here, endothelial cell derived PDGFB acts as a chemoattractant and mitogen for mural cells, which express PDGFRB (Andrae et al., 2008). PDGFRB signalling also induces autocrine $\mathrm{SHH}$ signalling in mural cells, which further stimulates their motility and proliferation (Yao et al., 2014).

In addition, DLL4 and serine/threonine kinase (AKT) $1 / 2$ signalling in endothelial cells induces the expression of the Notch ligand, Jagged1 (JAG1), which promotes mural cell coverage (Kerr et al., 2016; Pedrosa et al., 2015). The corresponding receptor for JAG1 on pericytes is NOTCH3. Mice lacking this receptor show reduced pericyte and smooth muscle cell coverage in their retinal vasculature (Henshall et al., 2015; Kofler et al., 2015; Liu et al., 2010). Correspondingly, heterozygous NOTCH3 mutations in humans leads to progressive degeneration of smooth muscle cells in small arterial vessels of the brain, a disorder called cerebral arteriopathy with subcortical infarcts and leukoencephalopathy (CADASIL) (Joutel, 2011). In the retina, CADASIL causes some detectable changes in the morphology of arterioles, but functional disturbances are minimal (Roine et al., 2006).

Endothelial-mural cell signalling also occurs in the reverse direction, from mural cells to endothelial cells. For instance, mural cells limit endothelial cell numbers, which is illustrated by excessive proliferation of endothelial cells after experimentally disrupting pericyte recruitment in the retinal vasculature (Hellström et al., 2001; Kofler et al., 2015; Ogura et al., 2017). At first sight, angiopoietin 1 (ANG1) seems a plausible candidate for mediating the stabilising influence of pericytes. It is secreted by mural cells, and the activation of its receptor (TIE2) on endothelial cells promotes vascular maturation and stabilisation (Augustin et al., 2009; Saharinen et al., 2008). However, more recent evidence suggests a more complex role of the ANG/TIE signalling system in retinal vasculature development and maturation (reviewed by Eklund et al., 2016). This is illustrated by genetic deletion experiments in mice, which have shown that ANG1 is only needed during early embryogenesis for heart development. If ANG1 is deleted after E13.5, mice are viable and have a perfectly normal retinal vasculature (Jeansson et al., 2011). Furthermore, deleting TIE2 in endothelial cells after birth (using a tamoxifen-inducible Crelox system), only delays primary plexus development, and has no obvious effects on vessel maturation or network remodelling of the retinal vasculature (Savant et al., 2015).

In contrast, retinal vasculature development is more noticeably affected by deletion of ANG2, which causes abnormal and reduced angiogenesis in the primary plexus, complete failure of deeper plexus development and persistent hyaloid vasculature (Gale et al., 2002; Hackett et al., 2002). Mechanistically this phenotype is not yet fully understood. This is partly due to the complex nature of the ANG/TIE signalling system, which can stabilise or destabilise vessels, depending on context. For instance, ANG2 has long been known to inhibit TIE2 signalling (Augustin et al., 2009; Yancopoulos et al., 2000), but under certain conditions, it can also act as an agonist (Yuan et al., 2009). This contextdependent activity is mediated by TIE1, which regulates ANG-induced trafficking of TIE2 (Korhonen et al., 2016; Savant et al., 2015). In adult mice, inflammation leads to the cleavage of the TIE1 extracellular domain, which turns ANG2 into a destabilising force. Conversely, under baseline conditions - with functional TIE1 present - ANG2 acts as a TIE2 agonist and stabilises vessels (Kim et al., 2016). Inducible deletion of TIE1 at birth increases vessel regression and endothelial apoptosis in the developing primary plexus (D'Amico et al., 2014; Savant et al., 2015), which could be an indication of an ANG2 stabilising activity during retinal vasculature development. On the other hand, destabilising properties of ANG2 might also be needed for deeper plexus development, to reactivate the quiescent vessels in the primary plexus when deeper plexus sprouting is initiated. However, ANG2 can also signal TIE2 independently via the integrins $\alpha v \beta 3, \alpha v \beta 5$ and $\alpha 5 \beta 1$ (Eklund et al., 2016; Felcht et al., 2012), and whether the failure of deeper plexus 
development in ANG2 knock-out mice is linked to abnormal integrin (see section 4.3) or TIE2 signalling is not yet known.

An important downstream target of the ANG/TIE signalling system is the transcription factor, forkhead box protein 01 (FOXO1); which regulates many genes associated with vessel remodelling, vascular destabilization, and endothelial cell proliferation and apoptosis (Augustin et al., 2009; Daly et al., 2004). TIE2 activation leads to an AKT-driven phosphorylation of FOXO1, which is then excluded from the nucleus and thereby rendered inactive (reviewed by Eijkelenboom and Burgering, 2013). In endothelial cells, this state has been linked to vessel maturation and stabilization; whereas nuclear localisation of FOXO1 is associated with vascular destabilisation and reduced junctional stability, as it is typically seen under inflammatory conditions (Augustin et al., 2009; Kim et al., 2016; Korhonen et al., 2016; Taddei et al., 2008). Furthermore, a recent study found that FOXO1 also influences retinal vasculature development, where it regulates the proliferation and metabolic activity of endothelial cells (Wilhelm et al., 2016). The study demonstrated that in the proliferative zone at the leading edge of the growing primary plexus (Fig. 1A), FOXO1 is phosphorylated - possibly mediated via VEGF and/or ANG/TIE signalling (Augustin et al., 2009; Simons et al., 2016) - and excluded from the nucleus. This prevents FOXO1 from antagonising the MYC proto-oncogene (MYC) (Eijkelenboom and Burgering, 2013), a transcription factor that normally promotes endothelial cell proliferation, growth, and metabolic activity. A de-repression of MYC via FOXO1 nuclear exclusion, therefore, promotes endothelial cell proliferation (Wilhelm et al., 2016). In contrast, in the remodelling zone, FOXO1 is localised in the nucleus of endothelial cells, consistent with low endothelial cell proliferation in this zone. This also fits with the destabilising activity of nuclear FOXO1 under inflammatory conditions mentioned above, since endothelial cells are dynamic in the remodelling zone (see section 5.1). However, whether FOXO1 also contributes to stable, long-term quiescence and vessel maturation is not yet clear.

\subsection{Vascular differentiation}

An integral aspect of vessel maturation is the differentiation of newly formed vessels into different types of mature vessels, such as capillaries, arteries, and veins. The best understood system of vascular differentiation is the formation of the dorsal aorta and cardinal vein. These vessels are formed during early embryogenesis by a process called vasculogenesis, which is based on migrating endothelial precursors (angioblasts) that form cords and assemble vessels de novo. It is well established that the arterial/venous fate assignment of these migrating angioblasts is critically regulated by DLL4/Notch signalling (Kim et al., 2008; Quillien et al., 2014; Siekmann and Lawson, 2007; Trindade et al., 2008).

The DLL4/Notch signalling pathway is also needed in the retinal vasculature for artery formation. The primary plexus of developing retinal vasculature lends itself as a useful model system to study artery/vein differentiation, because of its well-defined radial symmetry of arterial-venous loops and its peripheral-to-central gradient of vessel maturation (Fig. 1A). However, it is not formed by vasculogenesis but by angiogenesis, which is based on the extension of existing blood vessels (Fruttiger, 2002). As previously discussed, DLL4 is not only expressed by tip cells (see section 4.1), but is also found in arterial endothelial cells (Claxton and Fruttiger, 2004). Blocking DLL4 causes a reduction in arterial differentiation in the developing primary plexus, in addition to hyper-sprouting (Ridgway et al., 2006). The link between DLL4 expression in tip and arterial endothelial cells is not understood; however, the recent finding that arteries are formed by migrating endothelial cells during angiogenesis is intriguing. This insight is based on live imaging studies on the zebra fish fin, and on genetic labelling experiments in mouse retinal vasculature; both of which show that some endothelial cells at the tip position move within the existing vascular network into arteries via lateral migration, where they contribute towards vessel formation (Xu et al., 2014). Thus, migrating endothelial cells appear to contribute to artery formation in both processes, vasculogenesis and angiogenesis.

The SoxF family of transcription factors plays a crucial role for artery specific expression of DLL4 (Sacilotto et al., 2013). Furthermore, the SoxF protein SOX17 is highly expressed in arteries, and its genetic deletion in mice leads to impaired artery differentiation in the retinal vasculature - besides vascular hyper-sprouting (Corada et al., 2013), although this depends on the genetic background. The related SOXF family members SOX7, SOX17 and SOX18 can have redundant functions and combined inactivation of SOX7, SOX17, and SOX18 leads to an almost complete loss of radial arteries, irrespective of the background (Zhou et al., 2015). SOX17 is strongly induced by Norrin/WNT signalling, thus linking WNT and Notch signalling in artery specification and differentiation (Corada et al., 2014, 2013). As previously discussed (see section 4.3), Norrin/WNT has also been implicated in regulating the endothelial tip state and deeper plexus development in retinal vasculature. Interestingly, this signalling axis also has a third function in retinal vasculature development: driving the differentiation of vascular barrier properties in the brain (reviewed by Engelhardt and Liebner, 2014; Obermeier et al., 2013) and the retina (Wang et al., 2012; Zhou et al., 2014).

\section{Oxygen-induced retinopathy (OIR) and retinopathy of prematurity (ROP)}

During brain development, the brain's vasculature continuously grows to keep up with the steadily increasing brain volume. In comparison, retinal vascularisation is established more rapidly, when the metabolic supply for the retina switches from the hyaloid vasculature to the emerging retinal vasculature. A completely new network must be generated for a pre-existing, not yet vascularised but metabolically demanding tissue. Hence, the development of the retinal vasculature is uniquely sensitive to disturbances in angiogenesis and homeostasis. In humans, most retinal vasculature development is completed by birth (see section 1.1), but in preterm infants, external (such as increased 
oxygen concentrations) or internal influences (such as metabolic changes) can disturb retinal vasculature development and lead to ROP. In mice or rats, the retinal vasculature develops after birth, providing an accessible model system to study pathology in retinal vascular development.

\subsection{Mechanistic insights from the OIR model}

Oxygen, supplied by the developing retinal vessels, downregulates VEGF expression and shapes network development. This is illustrated by the capillary free spaces around arteries (Fig. 1A), where oxygen diffusion through the arterial wall into surrounding tissue prunes immature capillaries (see section 5.2). When mouse pups are exposed to increased atmospheric oxygen, tissue oxygenation can rise substantially via physically dissolved oxygen in plasma, independently of haemoglobin (which is already saturated). This is exploited in a popular OIR model (the "Smith model", Smith et al., 1994), where mouse pups are placed in $75 \%$ oxygen from P7 to P12 in order to induce an extreme form of capillary regression, which leads to a capillary free central retina. On return to room air (at P12), the resulting relative hypoxia triggers neovascularisation, which peaks at around P17 in severity and then spontaneously resolves by around 3-4 weeks after birth. The main vascular pathology in this model manifests itself in the form of vascular tufts, that penetrate the inner limiting membrane and grow towards the vitreous. This feature is widely used as a model for pathological angiogenesis in the retina (Connor et al., 2009; Stahl et al., 2010b).

There are several variations to the original "Smith model", including an earlier readout based on artery tortuosity (Scott et al., 2014) or altered hyperoxia schedules; $80 \%$ oxygen for 22 hours a day from P0-11, for example (Fletcher et al., 2010b). Alternatively, switching between $50 \%$ and $10 \%$ oxygen every 12 hours can be applied from birth till P14 (Penn et al., 1994), resulting in different vascular phenotypes compared to the original OIR model. A more severe pathology that persists into adulthood is induced by exposing mice to hyperoxia at PO for one or two weeks, resulting in retinal degeneration, scarring and detachment; culminating in a $50 \%$ reduction in retinal function and a persistent and hyperplastic hyaloid (Lajko et al., 2016; McMenamin et al., 2016).

A common feature of all OIR models is an initial, vesseldepleting phase and a second, neovascular phase. The mechanisms underlying the former are less well understood than the latter, however, it has been shown that experimental manipulations that stabilise vessels during the first phase indirectly affect the second phase by reducing the ensuing tissue hypoxia. Mice lacking prolyl hydroxylase 1 (PHD1, mediating degradation of HIFs), for example, show reduced vaso-obliteration during hyperoxia, a phenotype accompanied by increased VEGF levels (via HIF1A stabilisation) which aids vessel survival and leads to less severe neovascularisation (Huang et al., 2011a). Curiously, a second study found the same outcome in PHD2 knock-outs, but not in PHD1/PHD3 double knock-out mice (Duan et al., 2011). Systemic administration of a blocker that targets all three PHDs (dimethyloxaloylglycine, DMOG) also reduces vaso-obliteration during hyperoxia (Sears et al., 2008; Trichonas et al., 2013), but surprisingly, this effect seems to be driven by HIF stabilisation in the liver, independent of VEGF (Hoppe et al., 2016, 2014). Another factor that may destabilise immature retinal vessels is vasoconstriction, as it was shown that blockers of vasoconstriction (losartan or captopril) can prevent vessel-obliteration during the hyperoxic phase (Lobov et al., 2011). However, a comprehensive picture of the mechanisms responsible for the loss of vessels during phase one of the OIR model still needs to be established.

In contrast, neovascularisation (in the second phase) is a better understood outcome of OIR models. Here, the mechanisms that govern sprouting angiogenesis during normal retinal vascularisation (see chapter 4) provide a useful framework for understanding the causes of this vascular pathology. Not surprisingly, VEGF is critical. After the switch from hyperoxia to room air at P12 (as in the "Smith model"), the resulting hypoxia in the inner retina leads to pathologically high VEGF levels that prevent the tip/stalk selection machinery from working properly (Bentley et al., 2009; Gerhardt et al., 2003). Reducing VEGF levels from P12 onwards (e.g. with aflibercept or by genetic means) abrogates neovascular tufts and promotes normal angiogenesis, regenerating vessels in the previously capillary free regions (Huang et al., 2011b; Tokunaga et al., 2014; Weidemann et al., 2010). Similarly, hyperoxia treatment at P17 reduces VEGF levels and causes regression of neovascular tufts (Liu et al., 2013). The role of excessive tissue hypoxia is also illustrated in mutant mice with abnormally thin retinas (due to a mutation that causes perinatal photoreceptor degeneration). When these animals are put through the OIR protocol, oxygenation from the choroidal vasculature is sufficient to prevent excessive VEGF production, and the retinal vasculature regenerates normally without the formation of neovascular tufts (De Gooyer et al., 2006; Scott et al., 2014). Besides alterations to VEGF levels, there are several modulators of the tip/stalk machinery (see section 4.2) that can also influence neovascularisation in the OIR model; including intra-ocular injections of SEMA3E/A/C, which can prevent neovascular tuft formation (Fukushima et al., 2011; Joyal et al., 2011; Yang et al., 2015) and BMP9 which reduces neovascularization (Ntumba et al., 2016). On the other hand, Norrin/WNT signalling seems to promote pathological vascular growth in the OIR model, since blocking this pathway alleviates OIR pathology (Chen et al., 2011; Ohlmann et al., 2010).

In addition to the well-known components of sprouting angiogenesis (see chapter 4 ), there are many other factors that can modulate vascular behaviour in OIR (Cavallaro et al., 2014). For instance, insulin-like growth factor (IGF1) appears to facilitate retinal angiogenesis, since IGF1 knock-out mice exhibit delayed retinal vascularisation, despite normal VEGF levels (Hellstrom et al., 2001); and blocking or deleting IGF1 receptor reduces neovascularisation in the OIR model (Kondo et al., 2003; Smith et al., 1999). Erythropoietin (EPO) is another factor that can modulate the vasculature in OIR. 
During the first (vaso-obliterative) phase of OIR, administration of EPO protects retinal vessels; whilst during the second stage, exogenous EPO worsens neovascularisation and reducing endogenous EPO alleviates it (Chen et al., 2009, 2008). Furthermore, nutrition also has a role in the prevention of vascular pathology in OIR. This is demonstrated by mouse studies showing that increased dietary intake of omega 3 polyunsaturated fatty acids has a protective effect against neovascularisation in OIR (Connor et al., 2007). This process is mediated via an induction of peroxisome proliferator activated receptor gamma (PPARG) and adiponectin (APN) (Fu et al., 2015; Sapieha et al., 2011; Stahl et al., 2010c).

Many of the known factors that modulate vessel behaviour during OIR probably affect the vasculature indirectly through retinal glia or inflammatory cells. For example, the protective effects of angiotensin receptor blockers in OIR (reviewed by Fletcher et al., 2010a) are likely due to the prevention of retinal astrocyte loss, rather than a direct effect on the vessels themselves (Downie et al., 2008). Intravitreal injection of LIF, meanwhile, reduces vascular pathology in OIR via the growth stabilisation of retinal astrocytes, which express the receptor for LIF (see section $\mathbf{3 . 2}$ and Kubota et al., 2008); whilst intravitreal injection of astrocytes and astrocyte conditioned media in OIR rescues both endogenous astrocytes and microglia from hypoxic degeneration and reduced neovascularisation (Dorrell et al., 2010). Retinal astrocytes can work synergistically with microglia to mediate inflammatory damage by producing inflammatory cytokines and chemokines, which recruit myeloid derived inflammatory cells (de Hoz et al., 2016). Furthermore, resident microglia and invading monocytes have also been shown to be modulators of the neovascular response in mouse OIR (reviewed in Scott and Fruttiger, 2010).

It is also possible to modulate the neovascular response in OIR indirectly by manipulating hypoxia sensing or metabolic homeostasis in the entire retina. This can be achieved by interfering with the hypoxia sensing mechanisms in retinal cells (as with the experiments targeting phase 1 of the OIR described above). Several compounds that can antagonise HIF1A have also been shown to reduce neovascularisation after intraocular injection in OIR (Jo et al., 2014; Park et al., 2014; Yoshida et al., 2010; Zeng et al., 2017), as has Müller cell specific HIF1A deletion (Lin et al., 2011). Deleting HIF2A in retinal astrocytes also reduces neovascularisation, but interestingly HIF1A deletion does not (Weidemann et al., 2010). Apart from sensing oxygen levels, retinal cells can also use the concentration of metabolic intermediates to respond to changes in vascular supply. During the second, hypoxic phase in the OIR model, aerobic respiration is reduced and the Krebs cycle intermediate, succinate, builds up. RGCs respond to succinate build-up (via GPR91, see section 3.3) by upregulating angiogenic factors, including VEGF, contributing to neovascularisation (Sapieha et al., 2008). Thus, manipulating metabolic sensing or activity in the retina could also be a promising strategy to reduce hypoxia-induced neovascularisation.

\subsection{Clinical translation from OIR models to ROP}

First described in 1942 (Terry, 1942), ROP is a widely recognised, but potentially avoidable vitreoretinopathy affecting pre-term infants (Blencowe et al., 2013; William A Silverman, 1980). It is a vision-threatening disease in which abnormal vascular development occurs at the leading edge of the developing primary plexus (Blencowe et al., 2013; Good et al., 2005). The initial clinical observation in humans is a thin demarcation line (stage 1), appearing at the boundary between the vascularised and avascularised peripheral retina. This line can develop into a white or pink ridge (stage 2), from which neovascular vessels can start to grow (stage 3), which in turn can then lead to partial (stage 4) or full retinal detachment (stage 5). In addition, ROP classification also distinguishes three different geographical zones in which the pathologies occur, with the zone I being the most central and zone III the most peripheral. Signs of severe ROP include venous dilation and arteriolar tortuosity. If this is present in at least two quadrants, then the designation "plus" (+) is applied (International Committee for the Classification of Retinopathy of Prematurity, 2005).

The underlying pathobiological mechanisms of ROP (reviewed by Hartnett and Penn, 2012) have been elucidated by studies using OIR models in mice, rats and cats. Some of the insights gained in these model systems have directly led to advancements in the management of human ROP. For instance, in the early 1950s, Norman Ashton demonstrated through his work on kittens that high atmospheric oxygen during retinal vasculature development can lead to vascular regression, and that subsequent withdrawal of atmospheric hyperoxia can trigger hypoxia in the retina, leading to an excessive neovascular response (Ashton et al., 1954). The translation of that insight into the clinic has led to a much more careful and controlled use of oxygen supplementation in preterm infants, compared to the 1950s. It also led to the application of laser photocoagulation for treating pathological neovascularisation (stage 3 ) in ROP, which is still the gold-standard treatment (Mutlu and Sarici, 2013; Pertl et al., 2015). It works by ablating parts of the retina where neovascularisation is the highest, alleviating excessive hypoxia (and VEGF production) and allowing for normal vascularisation to continue in other parts of the retina (Rivera et al., 2011). The major drawback of this treatment is the permanent loss of vision at ablation sites (Mintz-Hittner et al., 2011; Pertl et al., 2015).

Furthermore, studies of the dynamics and the effects of VEGF expression in OIR animal models (see section 6.1) have led to numerous human trials evaluating the effectiveness of anti-VEGF agents in the treatment of ocular neovascular disease, including ROP. The BEAT-ROP study, a randomised controlled trial which compared anti-VEGF treatment to laser therapy (Mutlu and Sarici, 2013; Pertl et al., 2015), showed that intra-vitreal injection of bevacizumab (an antibody against VEGF) caused a statistically significant decrease in ROP recurrence in zone I, stage 3+ compared to laser therapy (42\% vs $6 \%$ ), but found no difference for zone 


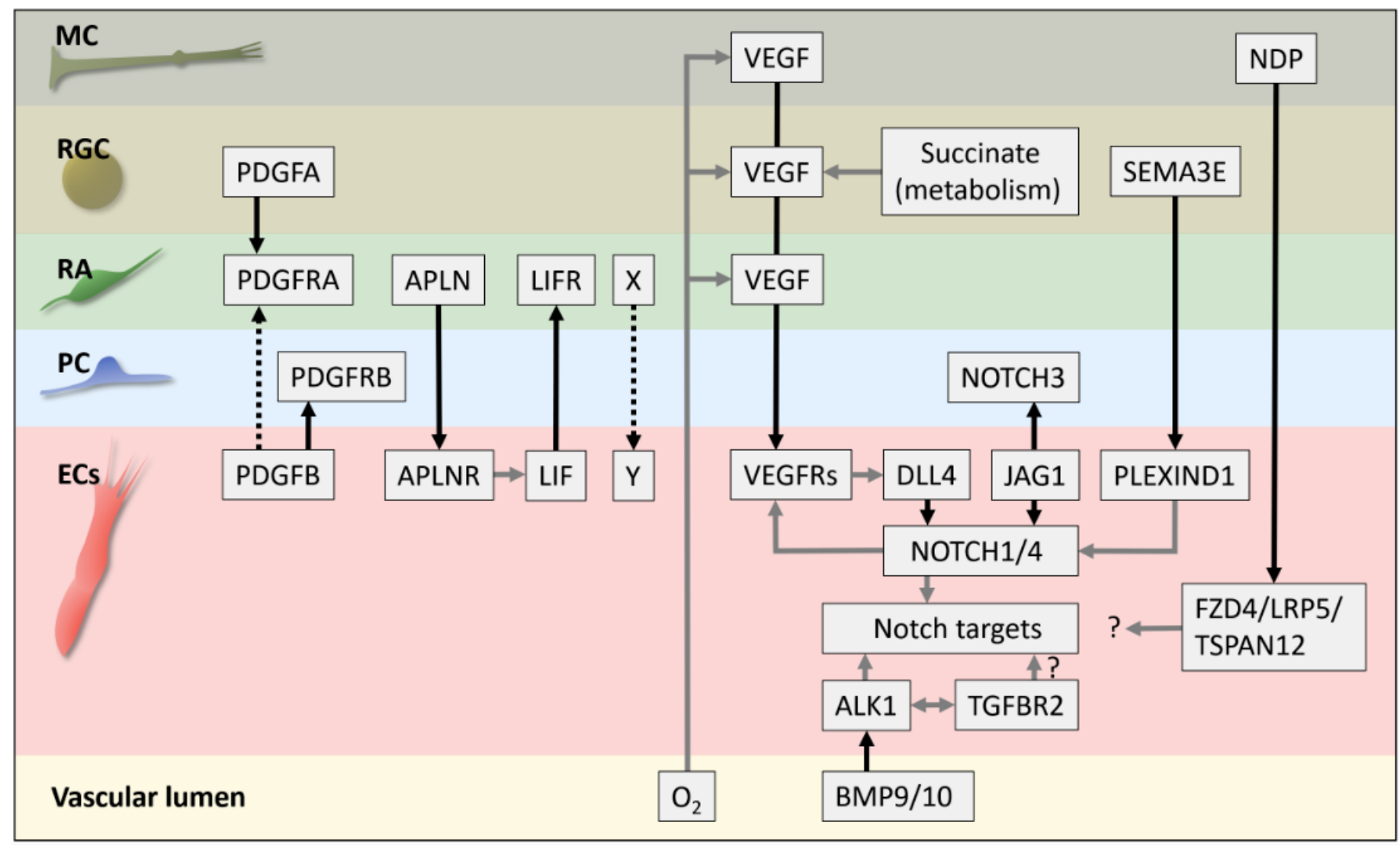

Fig. 7 Graphical summary of the major cell-cell interactions during retinal vascular development discussed in this review. Black arrows indicate direct ligand-receptor interactions (stippled in the case of hypothetical interaction), whereas grey arrows show indirect interactions (some of which are not entirely understood yet on a mechanistic level). Question marks indicate suspected but not yet confirmed influences. The ANG/TIE signalling system was not included here because its role in retinal vasculature development is not sufficiently understood yet. X: unknown astrocyte derived factor that is needed for primary plexus development, Y: receptor for factor X, MC: Müller cell, RGC: retinal ganglion cell, RA: retinal astrocyte, PC: pericyte, ECs: endothelial cells.

II, stage 3+ disease (Mintz-Hittner et al., 2011). Another smaller randomised controlled trial showed an increased rate of recurrence of ROP in zone II stage $3+$ disease compared to laser therapy, but also showed that in most cases recurrent ROP regressed with another anti-VEGF injection (Karkhaneh et al., 2016). These studies contradict reports in the literature (Dorta and Kychenthal, 2010; MintzHittner and Kuffel, 2008; Tahija et al., 2014; Wu et al., 2011), which suggest a uniform benefit of bevacizumab in both zone I and II. However, concerns regarding the systemic effects of these drugs - especially on the vessels of developing organs like the brain, lungs and kidneys - remain unaddressed, due to the short follow-up period of these studies (Pertl et al., 2015). The CARE-ROP trial (Clinical Trials Identifier: NCT02134457) aims to address some of these concerns, whilst also aiming to establish the efficacy of halfdose treatment.

To avoid the potential side effects of anti-VEGF agents, several other factors and signalling pathways have been proposed as possible targets for ROP management. None of these have yet been tested in phase 3 trials, but several phase $1 / 2$ trials have been started or completed. From such a trial, it has been suggested that blockers of beta-adrenergic receptors may be useful in ROP, based on their efficacy in model systems and in treating infantile haemangioma (reviewed by Casini et al., 2014). Although there are some conflicting results from studies in the mouse OIR model (J.
Chen et al., 2012; Filippi et al., 2012), data from early phase trials suggests some efficacy in ROP (Bancalari et al., 2016; Filippi et al., 2013).

Another example of ongoing efforts to translate efficacy in OIR models into the clinic, is the targeting of the IGF1 signalling pathway (see section 6.1). Proof of concept experiments in animals have been mirrored by observations in humans, with premature babies showing lower than normal levels of IGF1 for their gestational age, slowed retinal development and poor vascularisation (Hellstrom et al., 2001; Smith, 2005). This suggests that combined use of IGF1 supplementation (to support vascular growth) together with anti-VEGF medication or laser treatment to treat neovascularisation (should it occur) might provide a beneficial treatment approach (Stahl et al., 2014). Disappointingly, a recent phase 2 trial - treating premature infants with recombinant IGF1 - could not demonstrate an effect on ROP, but showed an improvement in comorbidities of ROP (severe bronchopulmonary dysplasia and severe intraventricular haemorrhage) (Hellström et al., 2016). However, changes in national guidelines for oxygen saturation targets may have affected this trial (Hellström et al., 2016), and a subsequent phase 3 trial is planned. It is also possible that additional, human specific complexities need to be considered before the effects of IGF1 signalling modulation in mice can be translated into the clinic (Liegl et al., 2016), including parameters such as postnatal growth 
retardation and reduced bioenergetics, which are associated with ROP and low IGF1 levels (Hellström et al., 2010; Stahl et al., 2010a). In this context, it is interesting that nutritional influences such as dietary supplementation with omega 3 polyunsaturated fatty acids can reduce pathology in mouse OIR (see section 6.1). Moreover, a recent human trial using fish-oil supplementation in low birth weight infants reduced the risk of ROP (Pawlik et al., 2014), demonstrating that manipulation of metabolism holds promising prospects for the future management of ROP.

\section{Conclusions and future directions}

Over the last two decades, a remarkably detailed understanding of the role of individual signalling pathways in retinal vascular development has emerged. Here we have discussed some of the key signals that mediate cell-cell interactions in this process (summarised in Fig. 7). However, it has also become increasingly evident that many of these signalling pathways have more than one function in development. VEGF, for example, can act as a chemokine, a mitogen, or a survival factor for endothelial cells, depending on the location within the developing vascular plexus. Consequently, genetic mutations or pharmacological interventions targeting a specific pathway uniformly, often impact on vascular network development by perturbations on multiple levels, making the outcomes difficult to interpret. Thus, an emerging challenge is to dissect the functions of these signalling pathways (and their modulators) within defined morphogenetic modules, such as tip/stalk switching, lumen formation, sprout fusion, vessel pruning, regression and maturation. For this endeavour, inducible genetic tools and genetic mosaic analysis are promising approaches, with the potential to drive this field forward. Also, the development of novel in vitro models could facilitate progress in this area. Furthermore, zebrafish is already proving to be an immensely powerful in vivo model for research on the general principles of vascular development. Although insights gained in fish (or non-ocular mammalian vasculature) might not necessarily translate into the mammalian retina. Moreover, it is important to keep in mind that this limitation also applies in the reverse direction; i.e. findings made in the retina may not apply to the systemic vasculature, because the retinal vasculature has unique properties. For instance, the multiple feedback loops between retinal astrocytes and retinal vessels (see chapter 3) may not have an equivalent in other vascular beds, and require caution when generalising experimental outcomes in retinal vasculature development.

For the study of pathological retinal vasculature development, the mouse OIR model has been a key tool; providing a particularly good readout for excessive VEGF activity. It is less clear how far OIR represents human ROP beyond this readout; however, work in this model system has produced numerous candidate drug targets for ROP beyond VEGF (including many that are not mentioned in this review), several of which have entered - or are being developed towards - further testing in human clinical trials. ROP continues to be an important cause of childhood blindness, especially in middle-income countries where poorly controlled oxygen use is still common. In addition to improvements in neonatal care, effective screening guidelines and provision of medical supplies to monitor oxygen delivery, the development of novel therapeutic options in ROP remains a key objective to help curb the worldwide epidemic of this sight-threatening condition.

\section{Acknowledgments}

We thank Sasha M. Woods and Marina Yasvoina for help with proof reading and editing, and Laura Ah-Kye for help with literature searches and manuscript writing. The preparation of this article has been supported by the Lowey Medical Research Institute, Fight for Sight, Diabetes UK and the NIHR Biomedical Research Centre for Ophthalmology, Moorfields Eye Hospital NHS Foundation Trust and UCL Institute of Ophthalmology.

\section{References}

Adams, R.H., Eichmann, A., 2010. Axon guidance molecules in vascular patterning. Cold Spring Harb. Perspect. Biol. 2, 1-19. doi:10.1101/cshperspect.a001875

Aghajanian, H., Choi, C., Ho, V.C., Gupta, M., Singh, M.K., Epstein, J.A., 2014. Semaphorin 3d and semaphorin 3e direct endothelial motility through distinct molecular signaling pathways. J. Biol. Chem. 289, 17971-17979. doi:10.1074/jbc.M113.544833

Allinson, K.R., Lee, H.S., Fruttiger, M., McCarty, J.H., Arthur, H.M., 2012. Endothelial expression of TGFbeta type II receptor is required to maintain vascular integrity during postnatal development of the central nervous system. PLoS.One. 7, e39336. doi:10.1371/journal.pone.0039336 [doi];PONE-D-1202874 [pii]

Anand-Apte, B., Hollyfield, J.G., 2010. Developmental Anatomy of the Retinal and Choroidal Vasculature. Encycl. Eye. 9-15. doi:10.1016/B978-0-12-374203-2.00169-X

Andrae, J., Ehrencrona, H., Gallini, R., Lal, M., Ding, H., Betsholtz, C., 2013. Analysis of Mice Lacking the Heparin-Binding Splice Isoform of Platelet-Derived Growth Factor A. Mol. Cell. Biol. 33, 4030-4040. doi:10.1128/MCB.00749-13

Andrae, J., Gallini, R., Betsholtz, C., 2008. Role of platelet-derived growth factors in physiology and medicine. Genes Dev. 22, 1276-1312. doi:10.1101/gad.1653708.revealing

Armulik, A., Genové, G., Betsholtz, C., 2011. Pericytes: Developmental, Physiological, and Pathological Perspectives, Problems, and Promises. Dev. Cell 21, 193-215. doi:10.1016/j.devcel.2011.07.001

Arnold, T.D., Ferrero, G.M., Qiu, H., Phan, I.T., Akhurst, R.J., Huang, E.J., Reichardt, L.F., 2012. Defective Retinal Vascular Endothelial Cell Development As a Consequence of Impaired Integrin V 8-Mediated Activation of Transforming Growth Factor- . J. Neurosci. 32, 1197-1206. doi:10.1523/JNEUROSCI.5648-11.2012

Arnold, T.D., Niaudet, C., Pang, M.-F., Siegenthaler, J., Gaengel, K., Jung, B., Ferrero, G.M., Mukouyama, Y. -s., Fuxe, J., Akhurst, R., Betsholtz, C., Sheppard, D., Reichardt, L.F., 2014. Excessive vascular sprouting underlies cerebral hemorrhage in mice lacking $\alpha$ V $\beta 8$-TGF $\beta$ signaling in the brain. Development 141, 4489-4499. doi:10.1242/dev.107193

Ashton, N., Pedler, C., 1962. Studies on developing retinal vessels IX. Reaction of endothelial cells to oxygen. Br. J. Ophthalmol. 46, 257-76.

Ashton, N., Ward, B., Serpell, G., 1954. Effect of Oxygen on 
Developing Retinal Vessels with Particular Reference to the Problem of Retrolental Fibroplasia. Br. J. Ophthalmol. 38, 397432. doi:10.1136/bjo.38.7.397

Aspalter, I.M., Gordon, E., Dubrac, A., Ragab, A., Narloch, J., Vizan, P., Geudens, I., Collins, R.T., Franco, C.A., Abrahams, C.L., Thurston, G., Fruttiger, M., Rosewell, I., Eichmann, A., Gerhardt, H., 2015. Alk1 and Alk5 inhibition by Nrp1 controls vascular sprouting downstream of Notch. Nat Commun 6, 7264. doi:10.1038/ncomms8264

Augustin, H.G., Koh, G.Y., Thurston, G., Alitalo, K., 2009. Control of vascular morphogenesis and homeostasis through the angiopoietin-Tie system. Nat. Rev. Mol. Cell Biol. 10, 165-77. doi:10.1038/nrm2639

Bai, Y., Ma, J., Guo, J., Wang, J., Zhu, M., Chen, Y., Le, Y.-Z., 2009. Müller cell-derived VEGF is a significant contributor to retinal neovascularization. J. Pathol. 219, 446-454. doi:10.1002/path.2611

Bajwa, A., Aman, R., Reddy, A.K., 2015. A comprehensive review of diagnostic imaging technologies to evaluate the retina and the optic disk. Int. Ophthalmol. 35, 733-755. doi:10.1007/s10792015-0087-1

Bancalari, A., Schade, R., Muñoz, T., Lazcano, C., Parada, R., Peña, R., 2016. Oral propranolol in early stages of retinopathy of prematurity. J. Perinat. Med. 44, 499-503. doi:10.1515/jpm2015-0357

Benedito, R., Roca, C., Sörensen, I., Adams, S., Gossler, A., Fruttiger, M., Adams, R.H., 2009. The Notch Ligands DII4 and Jagged1 Have Opposing Effects on Angiogenesis. Cell 137, 1124-1135. doi:10.1016/j.cell.2009.03.025

Benedito, R., Rocha, S.F., Woeste, M., Zamykal, M., Radtke, F., Casanovas, O., Duarte, A., Pytowski, B., Adams, R.H., 2012. Notch-dependent VEGFR3 upregulation allows angiogenesis without VEGF-VEGFR2 signalling. Nature 484, 110-114. doi:10.1038/nature10908

Bentley, K., Mariggi, G., Gerhardt, H., Bates, P.A., 2009. Tipping the balance: Robustness of tip cell selection, migration and fusion in angiogenesis. PLoS Comput. Biol. 5. doi:10.1371/journal.pcbi.1000549

Blanco, R., Gerhardt, H., 2013. VEGF and Notch in tip and stalk cell selection. Cold Spring Harb. Perspect. Med. 3, 1-20. doi:10.1101/cshperspect.a006569

Blencowe, H., Lawn, J.E., Vazquez, T., Fielder, A., Gilbert, C., 2013. Preterm-associated visual impairment and estimates of retinopathy of prematurity at regional and global levels for 2010. Pediatr. Res. 74, S1, 35-49. doi:10.1038/pr.2013.205

Brown, N.H., 2011. Extracellular matrix in development: Insights from mechanisms conserved between invertebrates and vertebrates. Cold Spring Harb. Perspect. Biol. 3, 1-14. doi:10.1101/cshperspect.a005082

Brown, W.R., Thore, C.R., 2011. Review: Cerebral microvascular pathology in ageing and neurodegeneration. Neuropathol. Appl. Neurobiol. 37, 56-74. doi:10.1111/j.13652990.2010.01139.x

Buehler, A., Sitaras, N., Favret, S., Bucher, F., Berger, S., Pielen, A., Joyal, J.S., Juan, A.M., Martin, G., Schlunck, G., Agostini, H.T., Klagsbrun, M., Smith, L.E.H., Sapieha, P., Stahl, A., 2013. Semaphorin $3 \mathrm{~F}$ forms an anti-angiogenic barrier in outer retina. FEBS Lett. 587, 1650-1655. doi:10.1016/j.febslet.2013.04.008

Carmeliet, P., Tessier-Lavigne, M., 2005. Common mechanisms of nerve and blood vessel wiring. Nature 436, 193-200. doi:10.1038/nature03875

Casini, G., Dal Monte, M., Fornaciari, I., Filippi, L., Bagnoli, P., 2014. The $\beta$-adrenergic system as a possible new target for pharmacologic treatment of neovascular retinal diseases. Prog. Retin. Eye Res. 42, 103-129. doi:10.1016/j.preteyeres.2014.06.001
Cavallaro, G., Filippi, L., Bagnoli, P., La Marca, G., Cristofori, G., Raffaeli, G., Padrini, L., Araimo, G., Fumagalli, M., Groppo, M., Dal Monte, M., Osnaghi, S., Fiorini, P., Mosca, F., 2014. The pathophysiology of retinopathy of prematurity: An update of previous and recent knowledge. Acta Ophthalmol. 92, 2-20. doi:10.1111/aos.12049

Charbel Issa, P., Gillies, M.C., Chew, E.Y., Bird, A.C., Heeren, T.F.C., Peto, T., Holz, F.G., Scholl, H.P.N., 2013. Macular telangiectasia type 2. Prog. Retin. Eye Res. 34, 49-77. doi:10.1016/j.preteyeres.2012.11.002

Chase, J., 1982. The Evolution of Retinal Vascularization in Mammals. Ophthalmology 89, 1518-1525. doi:10.1016/S0161-6420(82)34608-4

Chen, J., Connor, K.M., Aderman, C.M., Smith, L.E.H., 2008. Erythropoietin deficiency decreases vascular stability in mice. J.Clin.Invest 118, 526-533. doi:10.1172/JCI33813.526

Chen, J., Connor, K.M., Aderman, C.M., Willett, K.L., Aspegren, O.P., Smith, L.E.H., 2009. Suppression of retinal neovascularization by erythropoietin siRNA in a mouse model of proliferative retinopathy. Invest Ophthalmol.Vis.Sci. 50, 1329-1335. doi:10.1167/iovs.08-2521

Chen, J., Joyal, J.S., Hatton, C.J., Juan, A.M., Pei, D.T., Hurst, C.G., Xu, D., Stahl, A., Hellstrom, A., Smith, L.E.H., 2012a. Propranolol inhibition of $\beta$-adrenergic receptor does not suppress pathologic neovascularization in oxygen-induced retinopathy. Invest. Ophthalmol. Vis. Sci. 53, 2968-2977. doi:10.1167/iovs.12-9691

Chen, J., Stahl, A., Krah, N.M., Seaward, M.R., Dennison, R.J., Sapieha, P., Hua, J., Hatton, C.J., Juan, A.M., Aderman, C.M., Willett, K.L., Guerin, K.I., Mammoto, A., Campbell, M., Smith, L.E.H., 2011. Wnt signaling mediates pathological vascular growth in proliferative retinopathy. Circulation 124, 18711881. doi:10.1161/CIRCULATIONAHA.111.040337

Chen, Q., Jiang, L., Li, C., Hu, D., Bu, J. wen, Cai, D., Du, J. lin, 2012b. Haemodynamics-Driven Developmental Pruning of Brain Vasculature in Zebrafish. PLoS Biol. 10, e1001374. doi:10.1371/journal.pbio.1001374

Cheung, C.Y., Ikram, M.K., Chen, C., Wong, T.Y., 2017. Imaging retina to study dementia and stroke. Prog. Retin. Eye Res. 57, 89-107. doi:10.1016/j.preteyeres.2017.01.001

Claxton, S., Fruttiger, M., 2004. Periodic Delta-like 4 expression in developing retinal arteries. Gene Expr Patterns 5, 123-127. doi:10.1016/j.modgep.2004.05.004

Claxton, S., Fruttiger, M., 2003. Role of arteries in oxygen induced vaso-obliteration. Exp Eye Res 77, 305-311. doi:10.1016/S0014-4835(03)00153-2

Connor, K.M., Krah, N.M., Dennison, R.J., Aderman, C.M., Chen, J., Guerin, K.I., Sapieha, P., Stahl, A., Willett, K.L., Smith, L.E.H., 2009. Quantification of oxygen-induced retinopathy in the mouse: a model of vessel loss, vessel regrowth and pathological angiogenesis. Nat.Protoc. 4, 1565-1573. doi:10.1038/nprot.2009.187

Connor, K.M., SanGiovanni, J.P., Lofqvist, C., Aderman, C.M., Chen, J., Higuchi, A., Hong, S., Pravda, E.A., Majchrzak, S., Carper, D., Hellstrom, A., Kang, J.X., Chew, E.Y., Salem Jr., N., Serhan, C.N., Smith, L.E., 2007. Increased dietary intake of omega-3polyunsaturated fatty acids reduces pathological retinal angiogenesis. Nat.Med. 13, 868-873.

Coorey, N.J., Shen, W., Chung, S.H., Zhu, L., Gillies, M.C., 2012. The role of glia in retinal vascular disease. Clin. Exp. Optom. 95, 266-281. doi:10.1111/j.1444-0938.2012.00741.x

Corada, M., Morini, M.F., Dejana, E., 2014. Signaling pathways in the specification of arteries and veins. Arterioscler. Thromb. Vasc. Biol. 34, 2372-2377. doi:10.1161/ATVBAHA.114.303218

Corada, M., Orsenigo, F., Morini, M.F., Pitulescu, M.E., Bhat, G., Nyqvist, D., Breviario, F., Conti, V., Briot, A., Iruela-Arispe, M.L., Adams, R.H., Dejana, E., 2013. Sox17 is indispensable for 
acquisition and maintenance of arterial identity. Nat. Commun. 4, 2609. doi:10.1038/ncomms3609

D’Amico, G., Korhonen, E.A., Anisimov, A., Zarkada, G., Olopainen, T., Hägerling, R., Kiefer, F., Eklund, L., Sormunen, R., Elamaa, H., Brekken, R.A., Adams, R.H., Koh, G.Y., Saharinen, P., Alitalo, K., 2014. Tie1 deletion inhibits tumor growth and improves angiopoietin antagonist therapy. J. Clin. Invest. 124, 824-834. doi:10.1172/JCl68897

Dakubo, G.D., 2003. Retinal ganglion cell-derived sonic hedgehog signaling is required for optic disc and stalk neuroepithelial cell development. Development 130, 2967-2980. doi:10.1242/dev.00515

Daly, C., Wong, V., Burova, E., Wei, Y., Zabski, S., Griffiths, J., Lai, K.-M., Lin, H.C., loffe, E., Yancopoulos, G.D., Rudge, J.S., 2004. Angiopoietin-1 modulates endothelial cell function and gene expression via the transcription factor FKHR (FOXO1). Genes Dev. 18, 1060-1071. doi:10.1101/gad.1189704.Although

David, L., Mallet, C., Keramidas, M., Lamande, N., Gasc, J.M., Dupuis-Girod, S., Plauchu, H., Feige, J.J., Bailly, S., Lamandé, N., Gasc, J.M., Dupuis-Girod, S., Plauchu, H., Feige, J.J., Bailly, S., 2008. Bone morphogenetic protein-9 is a circulating vascular quiescence factor. Circ Res 102, 914-922. doi:10.1161/CIRCRESAHA.107.165530

David, L., Mallet, C., Mazerbourg, S., Feige, J.-J., Bailly, S., 2007. Identification of BMP9 and BMP10 as functional activators of the orphan activin receptor-like kinase 1 (ALK1) in endothelial cells. Blood 109, 1953-61. doi:10.1182/blood-2006-07-034124

De Bock, K., Georgiadou, M., Schoors, S., Kuchnio, A., Wong, B.W., Cantelmo, A.R., Quaegebeur, A., Ghesquière, B.,

Cauwenberghs, S., Eelen, G., Phng, L.K., Betz, I., Tembuyser, B., Brepoels, K., Welti, J., Geudens, I., Segura, I., Cruys, B., Bifari, F., Decimo, I., Blanco, R., Wyns, S., Vangindertael, J., Rocha, S., Collins, R.T., Munck, S., Daelemans, D., Imamura, H., Devlieger, R., Rider, M., Van Veldhoven, P.P., Schuit, F., Bartrons, R., Hofkens, J., Fraisl, P., Telang, S., Deberardinis, R.J., Schoonjans, L., Vinckier, S., Chesney, J., Gerhardt, H., Dewerchin, M., Carmeliet, P., 2013. Role of PFKFB3-driven glycolysis in vessel sprouting. Cell 154, 651-663. doi:10.1016/j.cell.2013.06.037

De Gooyer, T.E., Stevenson, K.A., Humphries, P., Simpson, D.A.C., Curtis, T.M., Gardiner, T.A., Stitt, A.W., 2006. Rod photoreceptor loss in Rho-/- mice reduces retinal hypoxia and hypoxia-regulated gene expression. Investig. Ophthalmol. Vis. Sci. 47, 5553-5560. doi:10.1167/iovs.06-0646

de Hoz, R., Rojas, B., Ramírez, A.I., Salazar, J.J., Gallego, B.I., Triviño, A., Ramírez, J.M., 2016. Retinal Macroglial Responses in Health and Disease. Biomed Res. Int. 2016, 2954721. doi:10.1155/2016/2954721

De Smet, F., Segura, I., De Bock, K., Hohensinner, P.J., Carmeliet, P., 2009. Mechanisms of vessel branching: Filopodia on endothelial tip cells lead the way. Arterioscler. Thromb. Vasc. Biol. 29, 639-649. doi:10.1161/ATVBAHA.109.185165

Dekker, R.J., van Thienen, J. V, Rohlena, J., de Jager, S.C., Elderkamp, Y.W., Seppen, J., de Vries, C.J.M., Biessen, E. a L., van Berkel, T.J.C., Pannekoek, H., Horrevoets, A.J.G., 2005. Endothelial KLF2 links local arterial shear stress levels to the expression of vascular tone-regulating genes. Am. J. Pathol. 167, 609-18. doi:10.1016/S0002-9440(10)63002-7

del Toro, R., Prahst, C., Mathivet, T., Siegfried, G., Kaminker, J.S., Larrivee, B., Breant, C., Duarte, A., Takakura, N., Fukamizu, A., Penninger, J., Eichmann, A., Del Toro, R., Prahst, C., Mathivet, T., Siegfried, G., Kaminker, J.S., Larrivee, B., Breant, C., Duarte, A., Takakura, N., Fukamizu, A., Penninger, J., Eichmann, A., 2010. Identification and functional analysis of endothelial tip cell-enriched genes. Blood 116, 4025-4033. doi:10.1182/blood-2010-02-270819

Domigan, C.K., Iruela-Arispe, M.L., 2014. Stealing VEGF from thy neighbor. Cell 159, 473-474. doi:10.1016/j.cell.2014.10.008
Donati, M.C., Carifi, G., Virgili, G., Menchini, U., 2005. Retinal angiomatous proliferation: Association with clinical and angiographic features. Ophthalmologica 220, 31-36. doi:10.1159/000089272

Dorrell, M.I., Aguilar, E., Friedlander, M., 2002. Retinal vascular development is mediated by endothelial filopodia, a preexisting astrocytic template and specific R-cadherin adhesion. Invest. Ophthalmol. Vis. Sci. 43, 3500-3510.

Dorrell, M.I., Aguilar, E., Jacobson, R., Trauger, S.A., Friedlander, J., Siuzdak, G., Friedlander, M., 2010. Maintaining retinal astrocytes normalizes revascularization and prevents vascular pathology associated with oxygen-induced retinopathy. Glia 58, 43-54. doi:10.1002/glia.20900

Dorrell, M.I., Aguilar, E., Jacobson, R., Yanes, O., Gariano, R., Heckenlively, J., Banin, E., Ramirez, G.A., Gasmi, M., Bird, A., Siuzdak, G., Friedlander, M., 2009. Antioxidant or neurotrophic factor treatment preserves function in a mouse model of neovascularization-associated oxidative stress. J. Clin. Invest. 119, 611-623. doi:10.1172/JCI35977

Dorta, P., Kychenthal, A., 2010. Treatment of type 1 retinopathy of prematurity with intravitreal bevacizumab (Avastin). Retina 30, S24-S31. doi:10.1097/IAE.0b013e3181ca1457

Downie, L.E., Pianta, M.J., Vingrys, A.J., Wilkinson-Berka, J.L., Fletcher, E.L., 2008. AT1 receptor inhibition prevents astrocyte degeneration and restores vascular growth in oxygen-induced retinopathy. Glia 56, 1076-1090. doi:10.1002/glia.20680

Duan, L.-J., Takeda, K., Fong, G.-H., 2014. Hypoxia inducible factor$2 \alpha$ regulates the development of retinal astrocytic network by maintaining adequate supply of astrocyte progenitors. PLoS One 9, e84736. doi:10.1371/journal.pone.0084736

Duan, L.J., Takeda, K., Fong, G.H., 2011. Prolyl hydroxylase domain protein 2 (PHD2) mediates oxygen-induced retinopathy in neonatal mice. Am. J. Pathol. 178, 1881-1890. doi:10.1016/j.ajpath.2010.12.016

Duke-Elder, n.d. System of Ophthalmology. Henry Kimpton and The CV Mosby Co., London.

Edwards, M.M., Mammadova-Bach, E., Alpy, F., Klein, A., Hicks, W.L., Roux, M., Simon-Assmann, P., Smith, R.S., Orend, G., Wu, J., Peachey, N.S., Naggert, J.K., Lefebvre, O., Nishina, P.M., 2010. Mutations in Lama1 Disrupt Retinal Vascular Development and Inner Limiting Membrane Formation. J. Biol. Chem. 285, 7697-7711. doi:10.1074/jbc.M109.069575

Edwards, M.M., McLeod, D.S., Li, R., Grebe, R., Bhutto, I., Mu, X., Lutty, G.A., 2012. The deletion of Math5 disrupts retinal blood vessel and glial development in mice. Exp. Eye Res. 96, 147156. doi:10.1016/j.exer.2011.12.005

Ehling, M., Adams, S., Benedito, R., Adams, R.H., 2013. Notch controls retinal blood vessel maturation and quiescence. Development 140, 3051-61. doi:10.1242/dev.093351

Eijkelenboom, A., Burgering, B.M.T., 2013. FOXOs: signalling integrators for homeostasis maintenance. Nat. Rev. Mol. Cell Biol. 14, 83-97. doi:10.1038/nrm3507

Eklund, L., Kangas, J., Saharinen, P., 2016. Angiopoietin-Tie signalling in the cardiovascular and lymphatic systems. Clin. Sci. 131, 87-103. doi:10.1042/CS20160129

el-Hifnawi, E., El-Hifnawi, A., Frankenberg, C., Keeler, C., 1994. Ultrastructure and regression of the tunica vasculosa lentis in newborn Wistar rats. Ann. Anat. 176, 143-149.

Engelhardt, B., Liebner, S., 2014. Novel insights into the development and maintenance of the blood-brain barrier. Cell Tissue Res. 1-13. doi:10.1007/s00441-014-1811-2

Fantin, A., Vieira, J.M., Plein, A., Denti, L., Fruttiger, M., Pollard, J.W., Ruhrberg, C., 2013. NRP1 acts cell autonomously in endothelium to promote tip cell function during sprouting angiogenesis. Blood 121, 2352-2362. doi:blood-2012-05424713 [pii];10.1182/blood-2012-05-424713 [doi]

Felcht, M., Luck, R., Schering, A., Seidel, P., Srivastava, K., Hu, J., 
Bartol, A., Kienast, Y., Vettel, C., Loos, E.K., Kutschera, S., Bartels, S., Appak, S., Besemfelder, E., Terhardt, D., Chavakis, E., Wieland, T., Klein, C., Thomas, M., Uemura, A., Goerdt, S., Augustin, H.G., 2012. Angiopoietin-2 differentially regulates angiogenesis through TIE2 and integrin signaling. J. Clin. Invest. 122, 1991-2005. doi:10.1172/JCI58832

Filippi, L., Cavallaro, G., Bagnoli, P., Dal Monte, M., Fiorini, P., Donzelli, G., Tinelli, F., Araimo, G., Cristofori, G., La Marca, G., Della Bona, M.L., La Torre, A., Fortunato, P., Furlanetto, S., Osnaghi, S., Mosca, F., 2013. Oral propranolol for retinopathy of prematurity: Risks, safety concerns, and perspectives. J. Pediatr. 163, 1570-1577.e6. doi:10.1016/j.jpeds.2013.07.049

Filippi, L., Dal Monte, M., Bagnoli, P., 2012. Different Efficacy of Propranolol in Mice with Oxygen-Induced Retinopathy: Could Differential Effects of Propranolol Be Related to Differences in Mouse Strains? Investig. Opthalmology Vis. Sci. 53, 74217423. doi:10.1167/iovs.12-11199

Fletcher, E., Phipps, J.A., Ward, M.M., Vessey, K.A., WilkinsonBerka, J.L., 2010a. The renin-angiotensin system in retinal health and disease: Its influence on neurons, glia and the vasculature. Prog. Retin. Eye Res. 29, 284-311. doi:10.1016/j.preteyeres.2010.03.003

Fletcher, E.L., Downie, L.E., Hatzopoulos, K., Vessey, K.A., Ward, M.M., Chow, C.L., Pianta, M.J., Vingrys, A.J., Kalloniatis, M., Wilkinson-Berka, J.L., 2010b. The significance of neuronal and glial cell changes in the rat retina during oxygen-induced retinopathy. Doc Ophthalmol 120, 67-86. doi:10.1007/s10633-009-9193-6

Franco, C.A., Jones, M.L., Bernabeu, M.O., Geudens, I., Mathivet, T., Rosa, A., Lopes, F.M., Lima, A.P., Ragab, A., Collins, R.T., Phng, L.K., Coveney, P. V., Gerhardt, H., 2015. Dynamic Endothelial Cell Rearrangements Drive Developmental Vessel Regression. PLoS Biol. 13, 1-19. doi:10.1371/journal.pbio.1002125

Fruttiger, M., 2007. Development of the retinal vasculature. Angiogenesis 10, 77-88. doi:10.1007/s10456-007-9065-1

Fruttiger, M., 2002. Development of the mouse retinal vasculature: angiogenesis versus vasculogenesis. Invest. Ophthalmol. Vis. Sci. 43, 522-7.

Fruttiger, M., Calver, A.R., Krüger, W.H., Mudhar, H.S., Michalovich, D., Takakura, N., Nishikawa, S., Richardson, W.D., 1996. PDGF mediates a neuron-astrocyte interaction in the developing retina. Neuron $17,1117-1131$.

Fu, Z., Lofqvist, C.A., Shao, Z., Sun, Y., Joyal, J.-S., Hurst, C.G., Cui, R.Z., Evans, L.P., Tian, K., SanGiovanni, J.P., Chen, J., Ley, D., Hansen Pupp, I., Hellstrom, A., Smith, L.E.H., 2015. Dietary $\omega-3$ polyunsaturated fatty acids decrease retinal neovascularization by adipose-endoplasmic reticulum stress reduction to increase adiponectin. Am. J. Clin. Nutr. 101, 87988. doi:10.3945/ajcn.114.099291

Fukushima, Y., Okada, M., Kataoka, H., Hirashima, M., Yoshida, Y., Mann, F., Gomi, F., Nishida, K., Nishikawa, S.I., Uemura, A., 2011. Sema3E-PlexinD1 signaling selectively suppresses disoriented angiogenesis in ischemic retinopathy in mice. J. Clin. Invest. 121, 1974-1985. doi:10.1172/JCI44900

Gale, N.W., Thurston, G., Hackett, S.F., Renard, R., Wang, Q., McClain, J., Martin, C., Witte, C., Witte, M.H., Jackson, D., Suri, C., Campochiaro, P.A., Wiegand, S.J., Yancopoulos, G.D., 2002. Angiopoietin-2 is required for postnatal angiogenesis and lymphatic patterning, and only the latter role is rescued by angiopoietin-1. Dev. Cell 3, 411-423. doi:10.1016/S15345807(02)00217-4

Gariano, R.F., 2003. Cellular mechanisms in retinal vascular development. Prog. Retin. Eye Res. 22, 295-306. doi:10.1016/S1350-9462(02)00062-9

Gariano, R.F., Gardner, T.W., 2005. Retinal angiogenesis in development and disease. Nature 438, 960-966. doi:10.1038/nature04482

Gariano, R.F., Iruela-Arispe, M.L., Hendrickson, A.E., 1994. Vascular development in primate retina: comparison of laminar plexus formation in monkey and human. Invest Ophthalmol.Vis.Sci. 35, 3442-3455.

Gariano, R.F., Sage, E.H., Kaplan, H.J., Hendrickson, A.E., 1996. Development of astrocytes and their relation to blood vessels in fetal monkey retina. Investig. Ophthalmol. Vis. Sci. 37, 2367-2375.

Gelfand, M. V, Hagan, N., Tata, A., Oh, W.J., Lacoste, B., Kang, K.T., Kopycinska, J., Bischoff, J., Wang, J.H., Gu, C., 2014. Neuropilin-1 functions as a VEGFR2 co-receptor to guide developmental angiogenesis independent of ligand binding. Elife 3, e03720. doi:10.7554/eLife.03720

Gerhardt, H., Golding, M., Fruttiger, M., Ruhrberg, C., Lundkvist, A., Abramsson, A., Jeltsch, M., Mitchell, C., Alitalo, K., Shima, D., Betsholtz, C., 2003. VEGF guides angiogenic sprouting utilizing endothelial tip cell filopodia. J Cell Biol 161, 11631177. doi:10.1083/jcb.200302047

Ghinia, M.G., Novelli, E., Sajgo, S., Badea, T.C., Strettoi, E., 2016. Brn3a and Brn3b knock-out mice display unvaried retinal fine structure despite major morphological and numerical alterations of ganglion cells. J. Comp. Neurol. 0, 1-25. doi:10.1002/cne.24072

Gilmour, D.F., 2014. Familial exudative vitreoretinopathy and related retinopathies. Eye 29, 1-14. doi:10.1038/eye.2014.70

Glinka, Y., Prud'homme, G.J., 2008. Neuropilin-1 is a receptor for transforming growth factor beta-1, activates its latent form, and promotes regulatory T cell activity. J Leukoc.Biol 84, 302310. doi:10.1189/jlb.0208090

Gnanaguru, G., Bachay, G., Biswas, S., Pinzón-Duarte, G., Hunter, D.D., Brunken, W.J., Pinzon-Duarte, G., Hunter, D.D., Brunken, W.J., Pinzón-Duarte, G., Hunter, D.D., Brunken, W.J., 2013. Laminins containing the $\beta 2$ and $\gamma 3$ chains regulate astrocyte migration and angiogenesis in the retina. Development 140, 2050-60. doi:10.1242/dev.087817

Good, W., Hardy, R., Dobson, V., Palmer, E., Phelps, D., Quintos, M., Tung, B., 2005. The incidence and course of retinopathy of prematurity: Findings from the Early Treatment for Retinopathy of Prematurity Study. Pediatrics 116, 15-23.

Gray, H., Lewis, W.H., 1918. Anatomy of the Human Body. Lea \& Febiger.

Gu, C., Rodriguez, E.R., Reimert, D. V, Shu, T., Fritzsch, B., Richards, L.J., Kolodkin, A.L., Ginty, D.D., 2003. Neuropilin-1 conveys semaphorin and VEGF signaling during neural and cardiovascular development. Dev.Cell 5, 45-57.

Guarani, V., Deflorian, G., Franco, C.A., Krüger, M., Phng, L.-K., Bentley, K., Toussaint, L., Dequiedt, F., Mostoslavsky, R., Schmidt, M.H.H., Zimmermann, B., Brandes, R.P., Mione, M., Westphal, C.H., Braun, T., Zeiher, A.M., Gerhardt, H., Dimmeler, S., Potente, M., 2011. Acetylation-dependent regulation of endothelial Notch signalling by the SIRT1 deacetylase. Nature 473, 234-8. doi:10.1038/nature09917

Hackett, S.F., Wiegand, S., Yancopoulos, G., Campochiaro, P.A., 2002. Angiopoietin-2 plays an important role in retinal angiogenesis. J. Cell. Physiol. 192, 182-187. doi:10.1002/jcp.10128

Hamm, M.J., Kirchmaier, B.C., Herzog, W., 2016. Sema3d controls collective endothelial cell migration by distinct mechanisms via nrp1 and plxnD1. J. Cell Biol. 215, 415-430. doi:10.1083/jcb.201603100

Hartnett, M.E., Penn, J.S., 2012. Mechanisms and management of retinopathy of prematurity. N.Engl.J.Med. 367, 2515-2526. doi:10.1056/NEJMra1208129 [doi]

Hellström, A., Ley, D., Hansen-Pupp, I., Hallberg, B., Ramenghi, L.A., Löfqvist, C., Smith, L.E.H.H., Hård, A.-L.L., 2016. IGF-I in the clinics: Use in retinopathy of prematurity. Growth Horm. 
IGF Res. 30-31, 75-80. doi:10.1016/j.ghir.2016.09.005

Hellström, a, Ley, D., Hansen-Pupp, I., Niklasson, a, Smith, L., Löfqvist, C., Hård, a-L., 2010. New insights into the development of retinopathy of prematurity--importance of early weight gain. Acta Paediatr. 99, 502-508. doi:10.1111/j.1651-2227.2009.01568.x

Hellstrom, a, Perruzzi, C., Ju, M., Engstrom, E., Hard, a L., Liu, J.L., Albertsson-Wikland, K., Carlsson, B., Niklasson, A., Sjodell, L., LeRoith, D., Senger, D.R., Smith, L.E., 2001. Low IGF-I suppresses VEGF-survival signaling in retinal endothelial cells: direct correlation with clinical retinopathy of prematurity. Proc. Natl. Acad. Sci. U. S. A. 98, 5804-8. doi:10.1073/pnas.101113998

Hellström, M., Gerhardt, H., Kalén, M., Li, X., Eriksson, U., Wolburg, H., Betsholtz, C., Hellstrom, M., Gerhardt, H., Kalen, M., Li, X., Eriksson, U., Wolburg, H., Betsholtz, C., 2001. Lack of pericytes leads to endothelial hyperplasia and abnormal vascular morphogenesis. J. Cell Biol. 152, 543-553. doi:10.1083/jcb.153.3.543

Hellström, M., Phng, L.-K.K., Hofmann, J.J., Wallgard, E., Coultas, L., Lindblom, P., Alva, J., Nilsson, A.-K.K., Karlsson, L., Gaiano, N., Yoon, K., Rossant, J., Iruela-Arispe, M.L., Kalén, M., Gerhardt, H., Betsholtz, C., Hellstrom, M., Phng, L.-K.K., Hofmann, J.J., Wallgard, E., Coultas, L., Lindblom, P., Alva, J., Nilsson, A.-K.K., Karlsson, L., Gaiano, N., Yoon, K., Rossant, J., Iruela-Arispe, M.L., Kalen, M., Gerhardt, H., Betsholtz, C., 2007. DII4 signalling through Notch1 regulates formation of tip cells during angiogenesis. Nature 445, 776-780. doi:10.1038/nature05571

Henshall, T.L., Keller, A., He, L., Johansson, B.R., Wallgard, E., Raschperger, E., Mae, M.A., Jin, S., Betsholtz, C., Lendahl, U., 2015. Notch 3 is necessary for blood vessel integrity in the central nervous system. Arterioscler. Thromb. Vasc. Biol. 35, 409-420. doi:10.1161/ATVBAHA.114.304849

Hirota, S., Clements, T.P., Tang, L.K., Morales, J.E., Lee, H.S., Oh, S.P., Rivera, G.M., Wagner, D.S., McCarty, J.H., 2015. Neuropilin-1 balances $\beta 8$ integrin-activated TGF $\beta$ signaling to control sprouting angiogenesis in the brain. Development. doi:10.1242/dev.113746

Hirota, S., Liu, Q., Lee, H.S., Hossain, M.G., Lacy-Hulbert, A., McCarty, J.H., 2011. The astrocyte-expressed integrin alphavbeta8 governs blood vessel sprouting in the developing retina. Development 138, 5157-5166. doi:138/23/5157 [pii] \r10.1242/dev.069153

Hoppe, G., Lee, T.J., Yoon, S., Yu, M., Peachey, N.S., Rayborn, M., Zutel, M.J., Trichonas, G., Au, J., Sears, J.E., 2014. Inducing a visceral organ to protect a peripheral capillary bed: Stabilizing hepatic HIF-1 $\alpha$ prevents oxygen-induced retinopathy. Am. J. Pathol. 184, 1890-1899. doi:10.1016/j.ajpath.2014.02.017

Hoppe, G., Yoon, S., Gopalan, B., Savage, A.R., Brown, R., Case, K., Vasanji, A., Chan, E.R., Silver, R.B., Sears, J.E., 2016. Comparative systems pharmacology of HIF stabilization in the prevention of retinopathy of prematurity. Proc. Natl. Acad. Sci. U. S. A. 113, E2516-E2525. doi:10.1073/pnas.1523005113

Huang, H., de Veire, S. Van, Dalal, M., Parlier, R., Semba, R.D., Carmeliet, P., Vinores, S.A., 2011a. Reduced retinal neovascularization, vascular permeability, and apoptosis in ischemic retinopathy in the absence of prolyl hydroxylase-1 due to the prevention of hyperoxia-induced vascular obliteration. Investig. Ophthalmol. Vis. Sci. 52, 7565-7573. doi:10.1167/iovs.11-8002

Huang, H., Shen, J., Vinores, S.A., 2011b. Blockade of VEGFR1 and 2 suppresses pathological angiogenesis and vascular leakage in the eye. PLoS One 6, e21411. doi:10.1371/journal.pone.0021411

Hughes, S., Yang, H., Chan-Ling, T., 2000. Vascularization of the human fetal retina: roles of vasculogenesis and angiogenesis.
Invest. Ophthalmol. Vis. Sci. 41, 1217-28.

International Committee for the Classification of Retinopathy of Prematurity, 2005. The International Classification of Retinopathy of Prematurity revisited. Arch. Ophthalmol. 123, 991-999. doi:10.1001/archopht.123.7.991

Ishida, S., Yamashiro, K., Usui, T., Kaji, Y., Ogura, Y., Hida, T., Honda, Y., Oguchi, Y., Adamis, A.P., 2003. Leukocytes mediate retinal vascular remodeling during development and vasoobliteration in disease. Nat Med 9, 781-788. doi:10.1038/nm877

Ito, M., Yoshioka, M., 1999. Regression of the hyaloid vessels and pupillary membrane of the mouse. Anat.Embryol.(Berl) 200, 403-411.

Jakobsson, L., Franco, C.A., Bentley, K., Collins, R.T., Ponsioen, B., Aspalter, I.M., Rosewell, I., Busse, M., Thurston, G., Medvinsky, A., Schulte-Merker, S., Gerhardt, H., 2010. Endothelial cells dynamically compete for the tip cell position during angiogenic sprouting. Nat.Cell Biol. 12, 943-953. doi:10.1038/ncb2103

Jeansson, M., Gawlik, A., Anderson, G., Li, C., Kerjaschki, D., Henkelman, M., Quaggin, S.E., 2011. Angiopoietin-1 is essential in mouse vasculature during development and in response to injury. J. Clin. Invest. 121, 2278-89. doi:10.1172/JCl46322DS1

Jin, Y., Kaluza, D., Jakobsson, L., 2014. VEGF, Notch and TGF $\beta / B M P s$ in regulation of sprouting angiogenesis and vascular patterning. Biochem. Soc. Trans. 42, 1576-1583. doi:10.1042/BST20140231

Jo, D.H., An, H., Chang, D.J., Baek, Y.Y., Cho, C.S., Jun, H.O., Park, S.J., Kim, J.H., Lee, H.Y., Kim, K.W., Lee, J., Park, H.J., Kim, Y.M., Suh, Y.G., Kim, J.H., 2014. Hypoxia-mediated retinal neovascularization and vascular leakage in diabetic retina is suppressed by HIF-1 $\alpha$ destabilization by SH-1242 and SH-1280, novel hsp90 inhibitors. J. Mol. Med. 92, 1083-1092. doi:10.1007/s00109-014-1168-8

Joutel, A., 2011. Pathogenesis of CADASIL: Transgenic and knockout mice to probe function and dysfunction of the mutated gene, Notch3, in the cerebrovasculature. BioEssays 33, 73-80. doi:10.1002/bies.201000093

Joyal, J.-S., Nim, S., Zhu, T., Sitaras, N., Rivera, J.C., Shao, Z., Sapieha, P., Hamel, D., Sanchez, M., Zaniolo, K., St-Louis, M., Ouellette, J., Montoya-Zavala, M., Zabeida, A., Picard, E., Hardy, P., Bhosle, V., Varma, D.R., Gobeil, F., Beauséjour, C., Boileau, C., Klein, W., Hollenberg, M., Ribeiro-da-Silva, A., Andelfinger, G., Chemtob, S., 2014. Subcellular localization of coagulation factor II receptor-like 1 in neurons governs angiogenesis. Nat. Med. 20, 1165-73. doi:10.1038/nm.3669

Joyal, J.-S., Sun, Y., Gantner, M.L., Shao, Z., Evans, L.P., Saba, N., Fredrick, T., Burnim, S., Kim, J.S., Patel, G., Juan, A.M., Hurst, C.G., Hatton, C.J., Cui, Z., Pierce, K.A., Bherer, P., Aguilar, E., Powner, M.B., Vevis, K., Boisvert, M., Fu, Z., Levy, E., Fruttiger, M., Packard, A., Rezende, F.A., Maranda, B., Sapieha, P., Chen, J., Friedlander, M., Clish, C.B., Smith, L.E.H., 2016. Retinal lipid and glucose metabolism dictates angiogenesis through the lipid sensor Ffar1. Nat. Med. doi:10.1038/nm.4059

Joyal, J.S., Sitaras, N., Binet, F., Rivera, J.C., Stahl, A., Zaniolo, K., Shao, Z., Polosa, A., Zhu, T., Hamel, D., Djavari, M., Kunik, D., Honoré, J.C., Picard, E., Zabeida, A., Varma, D.R., Hickson, G., Mancini, J., Klagsbrun, M., Costantino, S., Beauséjour, C., Lachapelle, P., Smith, L.E.H., Chemtob, S., Sapieha, P., 2011. Ischemic neurons prevent vascular regeneration of neural tissue by secreting semaphorin 3A. Blood 117, 6024-6035. doi:10.1182/blood-2010-10-311589

Junge, H.J., Yang, S., Burton, J.B., Paes, K., Shu, X., French, D.M., Costa, M., Rice, D.S., Ye, W., 2009. TSPAN12 regulates retinal vascular development by promoting Norrin- but not Wntinduced FZD4/beta-catenin signaling. Cell 139, 299-311. 
doi:10.1016/j.cell.2009.07.048

Kappas, N.C., Zeng, G., Chappell, J.C., Kearney, J.B., Hazarika, S., Kallianos, K.G., Patterson, C., Annex, B.H., Bautch, V.L., 2008. The VEGF receptor Flt-1 spatially modulates Flk-1 signaling and blood vessel branching. J. Cell Biol. 181, 847-858. doi:10.1083/jcb.200709114

Karkhaneh, R., Khodabande, A., Riazi-Eafahani, M., Roohipoor, R., Ghassemi, F., Imani, M., Dastjani Farahani, A., Ebrahimi Adib, N., Torabi, H., 2016. Efficacy of intravitreal bevacizumab for zone-II retinopathy of prematurity. Acta Ophthalmol. 94, e417-e420. doi:10.1111/aos.13008

Kawasaki, T., Kitsukawa, T., Bekku, Y., Matsuda, Y., Sanbo, M., Yagi, T., Fujisawa, H., 1999. A requirement for neuropilin-1 in embryonic vessel formation. Development 126, 4895-4902.

Kendall, R.L., Thomas, K.A., 1993. Inhibition of vascular endothelial cell growth factor activity by an endogenously encoded soluble receptor. Proc. Natl. Acad. Sci. U. S. A. 90, 10705-9. doi:10.1073/pnas.90.22.10705

Kerr, B.A., West, X.Z., Kim, Y.-W., Zhao, Y., Tischenko, M., Cull, R.M., Phares, T.W., Peng, X.-D., Bernier-Latmani, J., Petrova, T. V., Adams, R.H., Hay, N., Naga Prasad, S. V., Byzova, T. V., 2016. Stability and function of adult vasculature is sustained by Akt/Jagged1 signalling axis in endothelium. Nat. Commun. 7, 10960. doi:10.1038/ncomms10960

Kim, J., Oh, W.-J., Gaiano, N., Yoshida, Y., Gu, C., 2011a. Semaphorin 3E-Plexin-D1 signaling regulates VEGF function in developmental angiogenesis via a feedback mechanism. Genes Dev. 25, 1399-1411. doi:10.1101/gad.2042011

Kim, M., Allen, B., Korhonen, E.A., Nitschke, M., Yang, H.W., Baluk, P., Saharinen, P., Alitalo, K., Daly, C., Thurston, G., McDonald, D.M., 2016. Opposing actions of angiopoietin-2 on Tie2 signaling and FOXO1 activation. J. Clin. Invest. 126, 35113525. doi:10.1172/JCl84871

Kim, S.H., Turnbull, J., Guimond, S., 2011b. Extracellular matrix and cell signalling: The dynamic cooperation of integrin, proteoglycan and growth factor receptor. J. Endocrinol. 209, 139-151. doi:10.1530/JOE-10-0377

Kim, Y.H., Hu, H., Guevara-Gallardo, S., Lam, M.T.Y., Fong, S.-Y.Y., Wang, R.A., 2008. Artery and vein size is balanced by Notch and ephrin B2/EphB4 during angiogenesis. Development 135, 3755-3764. doi:10.1242/dev.022475

Kochhan, E., Lenard, A., Ellertsdottir, E., Herwig, L., Affolter, M., Belting, H.G., Siekmann, A.F., 2013. Blood Flow Changes Coincide with Cellular Rearrangements during Blood Vessel Pruning in Zebrafish Embryos. PLoS One 8, 1-7. doi:10.1371/journal.pone.0075060

Kofler, N.M., Cuervo, H., Uh, M.K., Murtomäki, A., Kitajewski, J., 2015. Combined deficiency of Notch1 and Notch3 causes pericyte dysfunction, models CADASIL, and results in arteriovenous malformations. Sci. Rep. 5, 16449. doi:10.1038/srep16449

Kondo, T., Vicent, D., Suzuma, K., Yanagisawa, M., King, G.L., Holzenberger, M., Kahn, C.R., 2003. Knockout of insulin and IGF-1 receptors on vascular endothelial cells protects against retinal neovascularization. J. Clin. Invest. 111, 1835-1842. doi:10.1172/JCI200317455.Introduction

Korhonen, E.A., Lampinen, A., Giri, H., Anisimov, A., Kim, M., Allen, B., Fang, S., D'Amico, G., Sipilä, T.J., Lohela, M., Strandin, T., Vaheri, A., Ylä-Herttuala, S., Koh, G.Y., McDonald, D.M., Alitalo, K., Saharinen, P., Mueller, S.B., Kontos, C.D., 2016. Tie1 controls angiopoietin function in vascular remodeling and inflammation. J. Clin. Invest. 126, 1-16. doi:10.1172/JCl89963

Korn, C., Augustin, H.G., 2015. Mechanisms of Vessel Pruning and Regression. Dev. Cell 34, 5-17. doi:10.1016/j.devcel.2015.06.004

Kubota, Y., Hirashima, M., Kishi, K., Stewart, C.L., Suda, T., 2008. Leukemia inhibitory factor regulates microvessel density by modulating oxygen-dependent VEGF expression in mice. J.Clin.Invest 118, 2393-2403. doi:10.1172/JCI34882DS1

Kuhnert, F., Mancuso, M.R., Shamloo, A., Wang, H.-T.T., Choksi, V., Florek, M., Su, H., Fruttiger, M., Young, W.L., Heilshorn, S.C., Kuo, C.J., 2010. Essential regulation of CNS angiogenesis by the orphan G protein-coupled receptor GPR124. Science (80-. ). 330, 985-9. doi:10.1126/science.1196554

Lajko, M., Cardona, H.J., Taylor, J.M., Shah, R.S., Farrow, K.N., Fawzi, A.A., 2016. Hyperoxia-Induced Proliferative Retinopathy: Early Interruption of Retinal Vascular Development with Severe and Irreversible Neurovascular Disruption. PLoS One 11, e0166886. doi:10.1371/journal.pone.0166886

Larrivée, B., Freitas, C., Suchting, S., Brunet, I., Eichmann, A., 2009. Guidance of vascular development: Lessons from the nervous system. Circ. Res. 104, 428-441. doi:10.1161/CIRCRESAHA.108.188144

Larrivée, B., Prahst, C., Gordon, E., del Toro, R., Mathivet, T., Duarte, A., Simons, M., Eichmann, A., 2012. ALK1 Signaling Inhibits Angiogenesis by Cooperating with the Notch Pathway. Dev. Cell 22, 489-500. doi:10.1016/j.devcel.2012.02.005

le Noble, F., Moyon, D., Pardanaud, L., Yuan, L., Djonov, V., Matthijsen, R., Bréant, C., Fleury, V., Eichmann, A., le, N.F., Moyon, D., Pardanaud, L., Yuan, L., Djonov, V., Matthijsen, R., Breant, C., Fleury, V., Eichmann, A., 2004. Flow regulates arterial-venous differentiation in the chick embryo yolk sac. Development 131, 361-375. doi:10.1242/dev.00929

Lee, S.H., Lee, S., Yang, H., Song, S., Kim, K., Saunders, T.L., Yoon, J.K., Koh, G.Y., Kim, I., 2014. Notch pathway targets proangiogenic regulator Sox17 to restrict angiogenesis. Circ. Res. 115, 215-226. doi:10.1161/CIRCRESAHA.115.303142

Liegl, R., Löfqvist, C., Hellström, A., Smith, L.E.H.H., 2016. IGF-1 in retinopathy of prematurity, a CNS neurovascular disease. Early Hum. Dev. 102, 13-19. doi:10.1016/j.earlhumdev.2016.09.008

Lin, C., Chen, M.H., Yao, E., Song, H., Gacayan, R., Hui, C. chung, Chuang, P.T., 2014. Differential regulation of Gli proteins by Sufu in the lung affects PDGF signaling and myofibroblast development. Dev. Biol. 392, 324-333. doi:10.1016/j.ydbio.2014.05.014

Lin, M., Chen, Y., Jin, J., Hu, Y., Zhou, K.K., Zhu, M., Le, Y.Z., Ge, J., Johnson, R.S., Ma, J.X., 2011. Ischaemia-induced retinal neovascularisation and diabetic retinopathy in mice with conditional knockout of hypoxia-inducible factor-1 in retinal Müller cells. Diabetologia 54, 1554-1566. doi:10.1007/s00125011-2081-0

Liu, H., Zhang, W., Kennard, S., Caldwell, R.B., Lilly, B., 2010. Notch3 is critical for proper angiogenesis and mural cell investment. Circ. Res. 107, 860-870. doi:10.1161/CIRCRESAHA.110.218271

Liu, H., Zhang, W., Xu, Z., Caldwell, R.W., Caldwell, R.B., Brooks, S.E., 2013. Hyperoxia causes regression of vitreous neovascularization by downregulating VEGF/VEGFR2 pathway. Investig. Ophthalmol. Vis. Sci. 54, 918-931. doi:10.1167/iovs.12-11291

Lobov, I.B., Cheung, E., Wudali, R., Cao, J., Halasz, G., Wei, Y., Economides, A., Lin, H.C., Papadopoulos, N., Yancopoulos, G.D., Wiegand, S.J., 2011. The DII4/notch pathway controls postangiogenic blood vessel remodeling and regression by modulating vasoconstriction and blood flow. Blood 117, 67286737. doi:10.1182/blood-2010-08-302067

Lobov, I.B., Rao, S., Carroll, T.J., Vallance, J.E., Ito, M., Ondr, J.K., Kurup, S., Glass, D.A., Patel, M.S., Shu, W., Morrisey, E.E., McMahon, A.P., Karsenty, G., Lang, R. a, 2005. WNT7b mediates macrophage-induced programmed cell death in patterning of the vasculature. Nature 437, 417-421. doi:10.1038/nature03928

Lobov, I.B., Renard, R. a, Papadopoulos, N., Gale, N.W., Thurston, 
G., Yancopoulos, G.D., Wiegand, S.J., 2007. Delta-like ligand 4 (DII4) is induced by VEGF as a negative regulator of angiogenic sprouting. Proc. Natl. Acad. Sci. U. S. A. 104, 3219-3224. doi:10.1073/pnas.0611206104

Luo, L., Uehara, H., Zhang, X., Das, S.K., Olsen, T., Holt, D., Simonis, J.M., Jackman, K., Singh, N., Miya, T.R., Huang, W., Ahmed, F., Bastos-Carvalho, A., Le, Y.Z., Mamalis, C., Chiodo, V.A., Hauswirth, W.W., Baffi, J., Lacal, P.M., Orecchia, A., Ferrara, N., Gao, G., Young-hee, K., Fu, Y., Owen, L., Albuquerque, R., Baehr, W., Thomas, K., Li, D.Y., Chalam, K. V., Shibuya, M., Grisanti, S., Wilson, D.J., Ambati, J., Ambati, B.K., 2013. Photoreceptor avascular privilege is shielded by soluble VEGF receptor-1. Elife 2013, 1-22. doi:10.7554/eLife.00324

Mann, I., 1950. The Development of the Human Eye. Grune \& Stratton, Inc, New York.

Marcelo, K.L., Goldie, L.C., Hirschi, K.K., 2013. Regulation of endothelial cell differentiation and specification. Circ. Res. 112, 1272-1287. doi:10.1161/CIRCRESAHA.113.300506

McCarty, J.H., 2009. Cell adhesion and signaling networks in brain neurovascular units. Curr Opin Hematol 16, 209-214. doi:10.1097/MOH.0b013e32832a07eb

McKenzie, J.A.G., Fruttiger, M., Abraham, S., Lange, C.A.K., Stone, J., Gandhi, P., Wang, X., Bainbridge, J., Moss, S.E., Greenwood, J., 2012. Apelin is required for non-neovascular remodeling in the retina. Am. J. Pathol. 180, 399-409. doi:10.1016/j.ajpath.2011.09.035

McMenamin, P.G., Kenny, R., Tahija, S., Lim, J., Naranjo Golborne, C., Chen, X., Bouch, S., Sozo, F., Bui, B., 2016. Early Postnatal Hyperoxia in Mice Leads to Severe Persistent Vitreoretinopathy. Investig. Opthalmology Vis. Sci. 57, 6513. doi:10.1167/iovs.16-19928

Mintz-Hittner, H.A., Kennedy, K.A., Chuang, A.Z., BEAT-ROP Cooperative Group, 2011. Efficacy of Intravitreal Bevacizumab for Stage 3+ Retinopathy of Prematurity. N. Engl. J. Med. 364, 603-615. doi:10.1056/NEJMoa1007374

Mintz-Hittner, H.A., Kuffel, R.R., 2008. Intravitreal injection of bevacizumab (Avastin) for treatment of stage 3 retinopathy of prematurity in zone I or posterior zone II. Retina $28,831-8$. doi:10.1097/IAE.0b013e31819a98a9

Miyawaki, T., Uemura, A., Dezawa, M., Yu, R.T., Ide, C., Nishikawa, S., Honda, Y., Tanabe, Y., Tanabe, T., 2004. Tlx, an orphan nuclear receptor, regulates cell numbers and astrocyte development in the developing retina. J Neurosci 24, 81248134. doi:10.1523/JNEUROSCI.2235-04.2004

Morcillo, J., Martínez-Morales, J.R., Trousse, F., Fermin, Y., Sowden, J.C., Bovolenta, P., 2006. Proper patterning of the optic fissure requires the sequential activity of BMP7 and $\mathrm{SHH}$. Development 133, 3179-90. doi:10.1242/dev.02493

Moya, M., Umans, L., Maas, E., Pereira, P.N.G., Beets, K., Francis, A., Sents, W., Moya, I.M., Umans, L., Maas, E., Pereira, P.N.G., Beets, K., Francis, A., Sents, W., Robertson, E.J., Mummery, C.L., Huylebroeck, D., Zwijsen, A., 2012. Stalk cell phenotype depends on integration of Notch and Smad1/5 signaling cascades. Dev. Cell 22, 501-514. doi:10.1016/j.devcel.2012.01.007

Mudhar, H.S., Pollock, R. a, Wang, C., Stiles, C.D., Richardson, W.D., 1993. PDGF and its receptors in the developing rodent retina and optic nerve. Development 118, 539-52.

Mutlu, F.M., Sarici, S.U., 2013. Treatment of retinopathy of prematurity: a review of conventional and promising new therapeutic options. Int. J. Ophthalmol. 6, 228-36. doi:10.3980/j.issn.2222-3959.2013.02.23

Nakamura-Ishizu, A., Kurihara, T., Okuno, Y., Ozawa, Y., Kishi, K., Goda, N., Tsubota, K., Okano, H., Suda, T., Kubota, Y., 2012. The formation of an angiogenic astrocyte template is regulated by the neuroretina in a HIF-1-dependent manner. Dev. Biol. 363, 106-114. doi:10.1016/j.ydbio.2011.12.027
Nornes, H.O., Dressler, G.R., Knapik, E.W., Deutsch, U., Gruss, P., 1990. Spatially and temporally restricted expression of Pax2 during murine neurogenesis. Development 109, 797-809.

Novodvorsky, P., Chico, T.J.A., 2014. The role of the transcription factor KLF2 in vascular development and disease, 1st ed, Progress in Molecular Biology and Translational Science. Elsevier Inc. doi:10.1016/B978-0-12-386930-2.00007-0

Ntumba, K., Akla, N., Oh, S.P., Eichmann, A., Larrivée, B., 2016. BMP9/ALK1 inhibits neovascularization in mouse models of age-related macular degeneration. Oncotarget 7, 5595755969. doi:10.18632/oncotarget.11182

Obermeier, B., Daneman, R., Ransohoff, R.M., 2013. Development, maintenance and disruption of the blood-brain barrier. Nat. Med. 19, 1584-96. doi:10.1038/nm.3407

Ochsenbein, A.M., Karaman, S., Proulx, S.T., Berchtold, M., Jurisic, G., Stoeckli, E.T., Detmar, M., 2016. Endothelial cell-derived semaphorin $3 \mathrm{~A}$ inhibits filopodia formation by blood vascular tip cells. Development 143, 589-594. doi:10.1242/dev.127670

Ogura, S., Kurata, K., Hattori, Y., Takase, H., Ishiguro-Oonuma, T., Hwang, Y., Ahn, S., Park, I., Ikeda, W., Kusuhara, S., Fukushima, Y., Nara, H., Sakai, H., Fujiwara, T., Matsushita, J., Ema, M., Hirashima, M., Minami, T., Shibuya, M., Takakura, N., Kim, P., Miyata, T., Ogura, Y., Uemura, A., 2017. Sustained inflammation after pericyte depletion induces irreversible blood-retina barrier breakdown. JCI Insight 2, 1-22. doi:10.1172/jci.insight.90905

Ohlmann, A., Seitz, R., Braunger, B., Seitz, D., Bosl, M.R., Tamm, E.R., 2010. Norrin Promotes Vascular Regrowth after OxygenInduced Retinal Vessel Loss and Suppresses Retinopathy in Mice. J. Neurosci. 30, 183-193. doi:10.1523/JNEUROSCI.321009.2010

Ohlmann, A.V.A. V, Scholz, M., Goldwich, A., Chauhan, B.K., Hudl, K., Ohlmann, A.V.A. V, Zrenner, E., Berger, W., Cvekl, A., Seeliger, M.W., Tamm, E.R., 2005. Ectopic norrin induces growth of ocular capillaries and restores normal retinal angiogenesis in Norrie disease mutant mice. J Neurosci 25, 1701-1710. doi:10.1523/JNEUROSCI.4756-04.2005

Okabe, K., Kobayashi, S., Yamada, T., Kurihara, T., Tai-Nagara, I., Miyamoto, T., Mukouyama, Y., Sato, T.N., Suda, T., Ema, M., Kubota, Y., 2014. Neurons limit angiogenesis by titrating VEGF in retina. Cell 159, 584-96. doi:10.1016/j.cell.2014.09.025

Pardali, E., Goumans, M.J., ten Dijke, P., 2010. Signaling by members of the TGF- $\beta$ family in vascular morphogenesis and disease. Trends Cell Biol. 20, 556-567. doi:10.1016/j.tcb.2010.06.006

Park, S.W., Kim, J.H., Kim, K.E., Jeong, M.H., Park, H., Park, B., Suh, Y.G., Park, W.J., Kim, J.H., 2014. Beta-lapachone inhibits pathological retinal neovascularization in oxygen-induced retinopathy via regulation of HIF-1a. J. Cell. Mol. Med. 18, 875-884. doi:10.1111/jcmm.12235

Pawlik, D., Lauterbach, R., Walczak, M., Hurkała, J., Sherman, M.P., 2014. Fish-Oil Fat Emulsion Supplementation Reduces the Risk of Retinopathy in Very Low Birth Weight Infants. J. Parenter. Enter. Nutr. 38, 711-716. doi:10.1177/0148607113499373

Pedrosa, A.R., Trindade, A., Fernandes, A.C., Carvalho, C., Gigante, J., Tavares, A.T., Diéguez-Hurtado, R., Yagita, H., Adams, R.H., Duarte, A., 2015. Endothelial jagged1 antagonizes DII4 regulation of endothelial branching and promotes vascular maturation downstream of DII4/Notch1. Arterioscler. Thromb. Vasc. Biol. 35, 1134-1146. doi:10.1161/ATVBAHA.114.304741

Penn, J.S., Henry, M.M., Tolman, B.L., 1994. Exposure to alternating hypoxia and hyperoxia causes severe proliferative retinopathy in the newborn rat. Pediatr. Res. 36, 724-31. doi:10.1203/00006450-199412000-00007

Pertl, L., Steinwender, G., Mayer, C., Hausberger, S., Poschl, E.M., Wackernagel, W., Wedrich, A., El-Shabrawi, Y., Haas, A., 2015. $A$ systematic review and meta-analysis on the safety of 
vascular endothelial growth factor (VEGF) inhibitors for the treatment of retinopathy of prematurity. PLoS One 10, 1-16. doi:10.1371/journal.pone.0129383

Phng, L.K., Potente, M., Leslie, J.D., Babbage, J., Nyqvist, D., Lobov, I., Ondr, J.K., Rao, S., Lang, R.A., Thurston, G., Gerhardt, H., 2009. Nrarp Coordinates Endothelial Notch and Wnt Signaling to Control Vessel Density in Angiogenesis. Dev. Cell 16, 70-82. doi:10.1016/j.devcel.2008.12.009

Phng, L.K., Stanchi, F., Gerhardt, H., 2013. Filopodia are dispensable for endothelial tip cell guidance. Development 140, 4031-4040. doi:10.1242/dev.097352

Pierce, E.A., Foley, E.D., Smith, L.E., 1996. Regulation of vascular endothelial growth factor by oxygen in a model of retinopathy of prematurity. Arch.Ophthalmol. 114, 1219-1228.

Pinzón-Duarte, G., Daly, G., Li, Y.N., Koch, M., Brunken, W.J., 2010. Defective formation of the inner limiting membrane in laminin $\beta 2$ - and $\beta 3-$ null mice produces retinal dysplasia. Investig. Ophthalmol. Vis. Sci. 51, 1773-1782. doi:10.1167/iovs.09-4645

Potente, M., Carmeliet, P., 2017. The Link Between Angiogenesis and Endothelial Metabolism. Annu. Rev. Physiol. 79, annurevphysiol-021115-105134. doi:10.1146/annurev-physiol-021115105134

Potente, M., Gerhardt, H., Carmeliet, P., 2011. Basic and therapeutic aspects of angiogenesis. Cell 146, 873-887. doi:S0092-8674(11)01009-9 [pii];10.1016/j.cell.2011.08.039 [doi]

Powner, M.B., Sim, D.A., Zhu, M., Nobre-Cardoso, J., Jones, R., Syed, A., Chang, A.A., Keane, P.A., Tufail, A., Egan, C.A., Fruttiger, M., 2016. Evaluation of Nonperfused Retinal Vessels in Ischemic Retinopathy. Investig. Opthalmology Vis. Sci. 57, 5031. doi:10.1167/iovs.16-20007

Provis, J.M., 2001. Development of the primate retinal vasculature. Prog. Retin. Eye Res. 20, 799-821.

Quillien, A., Moore, J.C., Shin, M., Siekmann, A.F., Smith, T., Pan, L.Y., Moens, C.B., Parsons, M.J., Lawson, N.D., 2014. Distinct Notch signaling outputs pattern the developing arterial system. Development 141, 1544-1552. doi:Doi 10.1242/Dev.099986

Rao, S., Chun, C., Fan, J., Kofron, J.M., Yang, M.B., Hegde, R.S., Ferrara, N., Copenhagen, D.R., Lang, R.A., 2013. A direct and melanopsin-dependent fetal light response regulates mouse eye development. Nature 494, 243-246. doi:10.1038/nature11823

Rao, S., Lobov, I.B., Vallance, J.E., Tsujikawa, K., Shiojima, I., Akunuru, S., Walsh, K., Benjamin, L.E., Lang, R.A., 2007. Obligatory participation of macrophages in an angiopoietin 2mediated cell death switch. Development 134, 4449-4458. doi:10.1242/dev.012187

Ricard, N., Ciais, D., Levet, S., Subileau, M., Mallet, C., Zimmers, T. a., Lee, S.J., Bidart, M., Feige, J.J., Bailly, S., 2012. BMP9 and BMP10 are critical for postnatal retinal vascular remodeling. Blood 119, 6162-6171. doi:10.1182/blood-2012-01-407593

Ridgway, J., Zhang, G., Wu, Y., Stawicki, S., Liang, W.C., Chanthery, Y., Kowalski, J., Watts, R.J., Callahan, C., Kasman, I., Singh, M., Chien, M., Tan, C., Hongo, J.A., De, S.F., Plowman, G., Yan, M., 2006. Inhibition of Dll4 signalling inhibits tumour growth by deregulating angiogenesis. Nature 444, 1083-1087.

Rivera, J.C., Sapieha, P., Joyal, J.S., Duhamel, F., Shao, Z., Sitaras, N., Picard, E., Zhou, E., Lachapelle, P., Chemtob, S., 2011. Understanding retinopathy of prematurity: Update on pathogenesis. Neonatology 100, 343-353. doi:10.1159/000330174

Rocha, S.F., Schiller, M., Jing, D., Li, H., Butz, S., Vestweber, D., Biljes, D., Drexler, H.C.A., Nieminen-Kelhä, M., Vajkoczy, P., Adams, S., Benedito, R., Adams, R.H., 2014. Esm1 modulates endothelial tip cell behavior and vascular permeability by enhancing VEGF bioavailability. Circ. Res. 115, 581-590.
doi:10.1161/CIRCRESAHA.115.304718

Roine, S., Harju, M., Kivelä, T.T., Pöyhönen, M., Nikoskelainen, E., Tuisku, S., Kalimo, H., Viitanen, M., Summanen, P.A., 2006. Ophthalmologic Findings in Cerebral Autosomal Dominant Arteriopathy with Subcortical Infarcts and Leukoencephalopathy. A Cross-sectional Study. Ophthalmology 113. doi:10.1016/j.ophtha.2006.03.030

Sacilotto, N., Monteiro, R., Fritzsche, M., Becker, P.W., SanchezDel-Campo, L., Liu, K., Pinheiro, P., Ratnayaka, I., Davies, B., Goding, C.R., Patient, R., Bou-Gharios, G., De Val, S., 2013. Analysis of Dll4 regulation reveals a combinatorial role for Sox and Notch in arterial development. Proc. Natl. Acad. Sci. U. S. A. 110, 11893-8. doi:10.1073/pnas.1300805110

Saharinen, P., Eklund, L., Miettinen, J., Wirkkala, R., Anisimov, A., Winderlich, M., Nottebaum, A., Vestweber, D., Deutsch, U., Koh, G.Y., Olsen, B.R., Alitalo, K., 2008. Angiopoietins assemble distinct Tie2 signalling complexes in endothelial cell-cell and cell-matrix contacts. Nat. Cell Biol. 10, 527-537. doi:10.1038/ncb1715

Saint-Geniez, M., D’Amore, P. a, 2004. Development and pathology of the hyaloid, choroidal and retinal vasculature. Int. J. Dev. Biol. 48, 1045-58. doi:10.1387/ijdb.041895ms

Sakimoto, S., Kidoya, H., Naito, H., Kamei, M., Sakaguchi, H., Goda, N., Fukamizu, A., Nishida, K., Takakura, N., 2012. A role for endothelial cells in promoting the maturation of astrocytes through the apelin/APJ system in mice. Development 139, 1327-1335. doi:10.1242/dev.072330

Sapieha, P., Sirinyan, M., Hamel, D., Zaniolo, K., Joyal, J.-S., Cho, J.H., Honoré, J.-C., Kermorvant-Duchemin, E., Varma, D.R., Tremblay, S., Leduc, M., Rihakova, L., Hardy, P., Klein, W.H., Mu, X., Mamer, O., Lachapelle, P., Di Polo, A., Beauséjour, C., Andelfinger, G., Mitchell, G., Sennlaub, F., Chemtob, S., 2008. The succinate receptor GPR91 in neurons has a major role in retinal angiogenesis. Nat. Med. 14, 1067-1076. doi:10.1038/nm.1873

Sapieha, P., Stahl, A., Chen, J., Seaward, M.R., Willett, K.L., Krah, N.M., Dennison, R.J., Connor, K.M., Aderman, C.M., Liclican, E., Carughi, A., Perelman, D., Kanaoka, Y., Sangiovanni, J.P., Gronert, K., Smith, L.E.H., 2011. 5-Lipoxygenase metabolite 4HDHA is a mediator of the antiangiogenic effect of $\omega-3$ polyunsaturated fatty acids. Sci. Transl. Med. 3, 69ra12. doi:10.1126/scitranslmed.3001571

Savant, S., La Porta, S., Budnik, A., Busch, K., Hu, J., Tisch, N., Korn, C., Valls, A.F., Benest, A. V., Terhardt, D., Qu, X., Adams, R.H., Baldwin, H.S., Ruiz de Almodovar, C., Rodewald, H.R., Augustin, H.G., 2015. The Orphan Receptor Tie1 Controls Angiogenesis and Vascular Remodeling by Differentially Regulating Tie2 in Tip and Stalk Cells. Cell Rep. 12, 1761-1773. doi:10.1016/j.celrep.2015.08.024

Schnitzer, J., 1987. Retinal astrocytes: their restriction to vascularized parts of the mammalian retina. Neurosci.Lett. 78, 29-34.

Schoors, S., Cantelmo, A.R., Georgiadou, M., Stapor, P., Wang, X., Quaegebeur, A., Cauwenberghs, S., Wong, B.W., Bifari, F., Decimo, I., Schoonjans, L., De Bock, K., Dewerchin, M., Carmeliet, P., 2014. Incomplete and transitory decrease of glycolysis: A new paradigm for anti-angiogenic therapy? Cell Cycle 13, 16-22. doi:10.4161/cc.27519

Schwarz, M., Cecconi, F., Bernier, G., Andrejewski, N., Kammandel, B., Wagner, M., Gruss, P., 2000. Spatial specification of mammalian eye territories by reciprocal transcriptional repression of Pax2 and Pax6. Development 127, 4325-4334.

Scott, A., Fruttiger, M., 2010. Oxygen-induced retinopathy: a model for vascular pathology in the retina. Eye (Lond). 24, 416-421. doi:10.1038/eye.2009.306

Scott, A., Powner, M.B., Fruttiger, M., 2014. Quantification of vascular tortuosity as an early outcome measure in oxygen 
induced retinopathy (OIR). Exp Eye Res 120, 55-60. doi:10.1016/j.exer.2013.12.020

Scott, A., Powner, M.B., Gandhi, P., Clarkin, C., Gutmann, D.H., Johnson, R.S., Ferrara, N., Fruttiger, M., 2010. Astrocytederived vascular endothelial growth factor stabilizes vessels in the developing retinal vasculature. PLoS.One. 5, e11863. doi:10.1371/journal.pone.0011863

Sears, J.E., Hoppe, G., Ebrahem, Q., Anand-Apte, B., Nand-Apte, B., 2008. Prolyl hydroxylase inhibition during hyperoxia prevents oxygen-induced retinopathy. Proc.Natl.Acad.Sci.U.S.A 105, 19898-19903. doi:10.1073/pnas.0805817105

Sehgal, R., Sheibani, N., Rhodes, S.J., Belecky Adams, T.L., 2009. BMP7 and SHH regulate Pax2 in mouse retinal astrocytes by relieving TLX repression. Dev. Biol. 332, 429-43. doi:10.1016/j.ydbio.2009.05.579

Semenza, G.L., 2011. Regulation of metabolism by hypoxiainducible factor 1. Cold Spring Harb Symp Quant Biol 76, 347353. doi:10.1101/sqb.2011.76.010678

Siekmann, A.F., Covassin, L., Lawson, N.D., 2008. Modulation of VEGF signalling output by the Notch pathway. BioEssays 30 , 303-313. doi:10.1002/bies.20736

Siekmann, A.F., Lawson, N.D., 2007. Notch signalling limits angiogenic cell behaviour in developing zebrafish arteries. Nature 445, 781-784. doi:10.1038/nature05577

Simons, M., Gordon, E., Claesson-Welsh, L., 2016. Mechanisms and regulation of endothelial VEGF receptor signalling. Nat. Rev. Mol. Cell Biol. 10, 611-25. doi:10.1038/nrm.2016.87

Smith, L.E., Shen, W., Perruzzi, C., Soker, S., Kinose, F., Xu, X., Robinson, G., Driver, S., Bischoff, J., Zhang, B., Schaeffer, J.M., Senger, D.R., 1999. Regulation of vascular endothelial growth factor-dependent retinal neovascularization by insulin-like growth factor-1 receptor. Nat. Med. 5, 1390-5. doi:10.1038/70963

Smith, L.E.H., 2005. IGF-1 and retinopathy of prematurity in the preterm infant. Biol. Neonate 88, 237-244. doi:10.1159/000087587

Smith, L.E.H., Wesolowski, E., McLellan, A., Kostyk, S.K., D’Amato, R., Sullivan, R., D'Amore, P. a., 1994. Oxygen-induced retinopathy in the mouse. Invest Ophthalmol.Vis.Sci. 35, 101111.

Stahl, A., Chen, J., Sapieha, P., Seaward, M.R., Krah, N.M., Dennison, R.J., Favazza, T., Bucher, F., Löfqvist, C., Ong, H., Hellström, A., Chemtob, S., Akula, J.D., Smith, L.E.H., 2010a. Postnatal weight gain modifies severity and functional outcome of oxygen-induced proliferative retinopathy. Am. J. Pathol. 177, 2715-23. doi:10.2353/ajpath.2010.100526

Stahl, A., Connor, K.M., Sapieha, P., Chen, J., Dennison, R.J., Krah, N.M., Seaward, M.R., Willett, K.L., Aderman, C.M., Guerin, K.I., Hua, J., Lofqvist, C., Hellstrom, A., Smith, L.E.H., 2010b. The mouse retina as an angiogenesis model. Investig. Ophthalmol. Vis. Sci. 51, 2813-2826. doi:10.1167/iovs.10-5176

Stahl, A., Hellstrom, A., Smith, L.E., 2014. IGF-1 and Anti-VEGF in ROP: Has the time come? Neonatology 106, 254-260. doi:10.1159/000365132.IGF-1

Stahl, A., Sapieha, P., Connor, K.M., Sangiovanni, J.P., Chen, J., Aderman, C.M., Willett, K.L., Krah, N.M., Dennison, R.J., Seaward, M.R., Guerin, K.I., Hua, J., Smith, L.E.H., 2010c. Short communication: PPARY mediates a direct antiangiogenic effect of $\omega 3$-PUFAs in proliferative retinopathy. Circ. Res. 107, 495500. doi:10.1161/CIRCRESAHA.110.221317

Stalmans, I., Ng, Y.S., Rohan, R., Fruttiger, M., Bouche, A., Yuce, A., Fujisawa, H., Hermans, B., Shani, M., Jansen, S., Hicklin, D., Anderson, D.J., Gardiner, T., Hammes, H.P., Moons, L., Dewerchin, M., Collen, D., Carmeliet, P., D'Amore, P.A., Bouché, A., Ÿuce, A., Fujisawa, H., Hermans, B., Shani, M., Jansen, S., Hicklin, D., Anderson, D.J., Gardiner, T., Hammes, H.P., Moons, L., Dewerchin, M., Collen, D., Carmeliet, P.,
Amore, P.A.D., 2002. Arteriolar and venular patterning in retinas of mice selectively expressing VEGF isoforms. J Clin Invest 109, 327-336. doi:10.1172/JCI200214362.Introduction

Stefater, J.A., Lewkowich, I., Rao, S., Mariggi, G., Carpenter, A.C., Burr, A.R., Fan, J., Ajima, R., Molkentin, J.D., Williams, B.O., Wills-Karp, M., Pollard, J.W., Yamaguchi, T., Ferrara, N., Gerhardt, H., Lang, R.A., 2011. Regulation of angiogenesis by a non-canonical Wnt-Flt1 pathway in myeloid cells. Nature 474 , 511-5. doi:10.1038/nature10085

Stenzel, D., Lundkvist, A., Sauvaget, D., Busse, M., Graupera, M., van der Flier, A., Wijelath, E.S., Murray, J., Sobel, M., Costell, M., Takahashi, S., Fassler, R., Yamaguchi, Y., Gutmann, D.H., Hynes, R.O., Gerhardt, H., 2011. Integrin-dependent and independent functions of astrocytic fibronectin in retinal angiogenesis. Development 138, 4451-4463. doi:10.1242/dev.071381

Stone, J., Dreher, Z., 1987. Relationship between astrocytes, ganglion cells and vasculature of the retina. J.Comp Neurol. 255, 35-49.

Stone, J., Itin, A., Alon, T., Pe'er, J., Gnessin, H., Chan-Ling, T., Keshet, E., 1995. Development of retinal vasculature is mediated by hypoxia-induced vascular endothelial growth factor (VEGF) expression by neuroglia. J.Neurosci. 15, 47384747.

Strasser, G. a., Kaminker, J.S., Tessier-Lavigne, M., 2010. Microarray analysis of retinal endothelial tip cells identifies CXCR4 as a mediator of tip cell morphology and branching. Blood 115, 5102-5110. doi:10.1182/blood-2009-07-230284

Suchting, S., Freitas, C., le Noble, F., Benedito, R., Bréant, C., Duarte, A., Eichmann, A., 2007. The Notch ligand Delta-like 4 negatively regulates endothelial tip cell formation and vessel branching. Proc. Natl. Acad. Sci. U. S. A. 104, 3225-3230. doi:10.1073/pnas.0611177104

Taddei, A., Giampietro, C., Conti, A., Orsenigo, F., Breviario, F., Pirazzoli, V., Potente, M., Daly, C., Dimmeler, S., Dejana, E., 2008. Endothelial adherens junctions control tight junctions by VE-cadherin-mediated upregulation of claudin-5. Nat. Cell Biol. 10, 923-34. doi:10.1038/ncb1752

Tahija, S.G., Hersetyati, R., Lam, G.C., Kusaka, S., McMenamin, P.G., 2014. Fluorescein angiographic observations of peripheral retinal vessel growth in infants after intravitreal injection of bevacizumab as sole therapy for zone I and posterior zone II retinopathy of prematurity. Br. J. Ophthalmol. 98, 507-512. doi:10.1136/bjophthalmol-2013304109

Tao, C., Zhang, X., 2016. Retinal Proteoglycans Act as Cellular Receptors for Basement Membrane Assembly to Control Astrocyte Migration and Angiogenesis. Cell Rep. 17, 1832-44. doi:10.1016/j.celrep.2016.10.035

Tao, C., Zhang, X., 2014. Development of astrocytes in the vertebrate eye. Dev. Dyn. 243, 1501-10. doi:10.1002/dvdy. 24190

Terry, T., 1942. Extreme Prematurity and Fibroblastic Overgrowth of Persistent Vascular Sheath Behind Each Crystalline Lens. Am. J. Ophthalmol. 25, 203-204.

Thurston, G., Kitajewski, J., 2008. VEGF and Delta-Notch: interacting signalling pathways in tumour angiogenesis. $\mathrm{Br}$. J. Cancer 99, 1204-9. doi:10.1038/sj.bjc.6604484

Tokunaga, C.C., Mitton, K.P., Dailey, W., Massoll, C., Roumayah, K., Guzman, E., Tarabishy, N., Cheng, M., Drenser, K.A., 2014. Effects of anti-VEGF treatment on the recovery of the developing retina following oxygen-induced retinopathy. Investig. Ophthalmol. Vis. Sci. 55, 1884-1892. doi:10.1167/iovs.13-13397

Trichonas, G., Lee, T.J., Hoppe, G., Au, J., Sears, J.E., 2013. Prolyl hydroxylase inhibition during hyperoxia prevents oxygeninduced retinopathy in the rat 50/10 model. Investig. 
Ophthalmol. Vis. Sci. 54, 4919-4926. doi:10.1167/iovs.1312171

Trindade, a., Ram Kumar, S., Scehnet, J.S., Lopes-da-Costa, L., Becker, J., Jiang, W., Liu, R., Gill, P.S., Duarte, A., Kumar, S.R., Scehnet, J.S., Lopes-da-Costa, L., Becker, J., Jiang, W., Liu, R., Gill, P.S., Duarte, A., 2008. Overexpression of delta-like 4 induces arterialization and attenuates vessel formation in developing mouse embryos. Blood 112, 1720-1729. doi:10.1182/blood-2007-09-112748

Tual-Chalot, S., Mahmoud, M., Allinson, K.R., Redgrave, R.E., Zhai, Z., Oh, S.P., Fruttiger, M., Arthur, H.M., 2014. Endothelial depletion of Acvrl1 in mice leads to arteriovenous malformations associated with reduced endoglin expression. PLoS One 9. doi:10.1371/journal.pone.0098646

Ubezio, B., Blanco, R.A., Geudens, I., Stanchi, F., Mathivet, T., Jones, M.L., Ragab, A., Bentley, K., Gerhardt, H., 2016. Synchronization of endothelial DII4-Notch dynamics switch blood vessels from branching to expansion. Elife 5 . doi:10.7554/eLife.12167

Udan, R.S., Vadakkan, T.J., Dickinson, M.E., 2013. Dynamic responses of endothelial cells to changes in blood flow during vascular remodeling of the mouse yolk sac. Development 140 4041-4050. doi:10.1242/dev.096255

Uemura, A., Kusuhara, S., Wiegand, S.J., Yu, R.T., Nishikawa, S., 2006. Tlx acts as a proangiogenic switch by regulating extracellular assembly of fibronectin matrices in retinal astrocytes. J. Clin. Invest. 116, 369-377. doi:10.1172/JCl25964.In

Usui, Y., Westenskow, P.D., Kurihara, T., Aguilar, E., Sakimoto, S., Paris, L.P., Wittgrove, C., Feitelberg, D., Friedlander, M.S.H.M.M.S.H., Moreno, S.K., Dorrell, M.I., Friedlander, M.S.H.M.M.S.H., 2015. Neurovascular crosstalk between interneurons and capillaries is required for vision. J. Clin. Invest. 125, 2335-2346. doi:10.1172/JCl80297

Vempati, P., Popel, A.S., Mac Gabhann, F., 2011. Formation of VEGF isoform-specific spatial distributions governing angiogenesis: computational analysis. BMC Syst. Biol. 5, 59. doi:10.1186/1752-0509-5-59

Wacker, A., Gerhardt, H., Phng, L.K., 2014. Tissue guidance without filopodia. Commun. Integr. Biol. 7. doi:10.4161/cib.28820

Wang, Y., Rattner, A., Zhou, Y., Williams, J., Smallwood, P.M., Nathans, J., 2012. Norrin/Frizzled4 signaling in retinal vascular development and blood brain barrier plasticity. Cell 151, 1332-1344. doi:10.1016/j.cell.2012.10.042

Watson, E.C., Koenig, M.N., Grant, Z.L., Whitehead, L., Trounson, E., Dewson, G., Coultas, L., 2016. Apoptosis regulates endothelial cell number and capillary vessel diameter but not vessel regression during retinal angiogenesis. Development 143, 2973-2982. doi:10.1242/dev.137513

Weidemann, A., Krohne, T.U., Aguilar, E., Kurihara, T., Takeda, N., Dorrell, M.I., Simon, M.C., Haase, V.H., Friedlander, M., Johnson, R.S., 2010. Astrocyte hypoxic response is essential for pathological but not developmental angiogenesis of the retina. Glia 58, 1177-1185. doi:10.1002/glia.20997

West, H., Richardson, W.D., Fruttiger, M., 2005. Stabilization of the retinal vascular network by reciprocal feedback between blood vessels and astrocytes. Development 132, 1855-1862. doi:10.1242/dev.01732

Wijelath, E.S., Rahman, S., Namekata, M., Murray, J., Nishimura, T., Mostafavi-Pour, Z., Patel, Y., Suda, Y., Humphries, M.J., Sobel, M., 2006. Heparin-II domain of fibronectin is a vascular endothelial growth factor-binding domain: Enhancement of VEGF biological activity by a singular growth factor/matrix protein synergism. Circ. Res. 99, 853-860. doi:10.1161/01.RES.0000246849.17887.66

Wilhelm, K., Happel, K., Eelen, G., Schoors, S., Oellerich, M.F., Lim,
R., Zimmermann, B., Aspalter, I.M., Franco, C.A., Boettger, T., Braun, T., Fruttiger, M., Rajewsky, K., Keller, C., Brüning, J.C., Gerhardt, H., Carmeliet, P., Potente, M., 2016. FOXO1 couples metabolic activity and growth state in the vascular endothelium. Nature 529, 1-18. doi:10.1038/nature16498

William A Silverman, 1980. Retrolental fibroplasia: A modern parable, 1st ed. Grune \& Stratton Inc, New York, New York.

Winkler, E. a, Bell, R.D., Zlokovic, B. V, 2011. Central nervous system pericytes in health and disease. Nat. Neurosci. 14, 1398-1405. doi:10.1038/nn.2946

Wu, W.C., Yeh, P.T., Chen, S.N., Yang, C.M., Lai, C.C., Kuo, H.K., 2011. Effects and complications of bevacizumab use in patients with retinopathy of prematurity: A multicenter study in Taiwan. Ophthalmology 118, 176-183.

doi:10.1016/j.ophtha.2010.04.018

Xie, J., Aszterbaum, M., Zhang, X., Bonifas, J.M., Zachary, C., Epstein, E., McCormick, F., 2001. A role of PDGFRalpha in basal cell carcinoma proliferation. Proc. Natl. Acad. Sci. U. S. A. 98, 9255-9. doi:10.1073/pnas.151173398

Xu, C., Hasan, S.S., Schmidt, I., Rocha, S.F., Pitulescu, M.E., Bussmann, J., Meyen, D., Raz, E., Adams, R.H., Siekmann, A.F., 2014. Arteries are formed by vein-derived endothelial tip cells. Nat. Commun. 5, 5758. doi:10.1038/ncomms6758

$\mathrm{Xu}$, Q., Wang, Y., Dabdoub, A., Smallwood, P.M., Williams, J., Woods, C., Kelley, M.W., Jiang, L., Tasman, W., Zhang, K., Nathans, J., 2004. Vascular development in the retina and inner ear: control by Norrin and Frizzled-4, a high-affinity ligand-receptor pair. Cell 116, 883-895.

Yancopoulos, G.D., Davis, S., Gale, N.W., Rudge, J.S., Wiegand, S.J., Holash, J., 2000. Vascular-specific growth factors and blood vessel formation. Nature 407, 242-8. doi:10.1038/35025215

Yang, W.-J.W.-J., Hu, J., Uemura, A., Tetzlaff, F., Augustin, H.G., Fischer, A., 2015. Semaphorin-3C signals through Neuropilin-1 and PlexinD1 receptors to inhibit pathological angiogenesis. EMBO Mol. Med. 7, 1267-1284. doi:10.15252/emmm.201404922

Yang, X.J., 2004. Roles of cell-extrinsic growth factors in vertebrate eye pattern formation and retinogenesis. Semin. Cell Dev. Biol. 15, 91-103. doi:10.1016/j.semcdb.2003.09.004

Yao, Q., Renault, M., Chapouly, C., Vandierdonck, S., Belloc, I., Daniel-lamazi, J., Laffargue, M., Merched, A., Desgranges, C., 2014. Sonic hedgehog mediates a novel pathway of PDGF-BB dependent vessel maturation. Blood 123, 2429-2437. doi:10.1182/blood-2013-06-508689.The

Ye, W., 2016. The Complexity of Translating Anti-angiogenesis Therapy from Basic Science to the Clinic. Dev. Cell 37, 114125. doi:10.1016/j.devcel.2016.03.015

Ye, X., Wang, Y., Cahill, H., Yu, M., Badea, T.C., Smallwood, P.M., Peachey, N.S., Nathans, J., 2009. Norrin, frizzled-4, and Lrp5 signaling in endothelial cells controls a genetic program for retinal vascularization. Cell 139, 285-298. doi:10.1016/j.cell.2009.07.047

Yoshida, T., Zhang, H., Iwase, T., Shen, J., Semenza, G.L., Campochiaro, P.A., 2010. Digoxin inhibits retinal ischemiainduced HIF-1alpha expression and ocular neovascularization. FASEB J. 24, 1759-67. doi:10.1096/fj.09-145664

Yoshikawa, Y., Yamada, T., Tai-Nagara, I., Okabe, K., Kitagawa, Y., Ema, M., Kubota, Y., 2016. Developmental regression of hyaloid vasculature is triggered by neurons. J. Exp. Med. 213, 1175-83. doi:10.1084/jem.20151966

Yuan, H.T., Khankin, E. V, Karumanchi, S.A., Parikh, S.M., 2009. Angiopoietin 2 Is a Partial Agonist/Antagonist of Tie2 Signaling in the Endothelium. Mol. Cell. Biol. 29, 2011-2022. doi:10.1128/MCB.01472-08

Zarkada, G., Heinolainen, K., Makinen, T., Kubota, Y., Alitalo, K., 2015. VEGFR3 does not sustain retinal angiogenesis without VEGFR2. Proc. Natl. Acad. Sci. U. S. A. 112, 761-6. 
doi:10.1073/pnas.1423278112

Zeng, M., Shen, J., Liu, Y., Lu, L.Y., Ding, K., Fortmann, S.D., Khan, M., Wang, J., Hackett, S.F., Semenza, G.L., Campochiaro, P.A., 2017. The HIF-1 antagonist acriflavine: visualization in retina and suppression of ocular neovascularization. J. Mol. Med. 95, 417-429. doi:10.1007/s00109-016-1498-9

Zhao, L., Zevallos, S.E., Rizzoti, K., Jeong, Y., Lovell-Badge, R., Epstein, D.J., 2012. Disruption of SoxB1-Dependent Sonic hedgehog Expression in the Hypothalamus Causes Septo-optic Dysplasia. Dev. Cell 22, 585-596. doi:10.1016/j.devcel.2011.12.023

Zhou, Y., Nathans, J., 2014. Gpr124 Controls CNS Angiogenesis and Blood-Brain Barrier Integrity by Promoting Ligand-Specific Canonical Wnt Signaling. Dev. Cell 31, 248-256. doi:10.1016/j.devcel.2014.08.018

Zhou, Y., Wang, Y., Tischfield, M., Williams, J., Smallwood, P.M., Rattner, A., Taketo, M.M., Nathans, J., 2014. Canonical WNT signaling components in vascular development and barrier formation. J Clin Invest 124, 3825-3846. doi:10.1172/JCI76431

Zhou, Y., Williams, J., Smallwood, P.M., Nathans, J., 2015. Sox7, Sox17, and Sox18 cooperatively regulate vascular development in the mouse retina. PLoS One 10, 1-22. doi:10.1371/journal.pone.0143650

Zhu, M., Madigan, M.C., van Driel, D., Maslim, J., Billson, F.A., Provis, J.M., Penfold, P.L., 2000. The Human Hyaloid System: Cell Death and Vascular Regression. Exp. Eye Res. 70, 767-776. doi:10.1006/exer.2000.0844 